Published paper available: Igarashi, T., Okuda, S., \& Sasahara, K. (2022). Development of the Japanese Version of the Linguistic Inquiry and Word Count Dictionary 2015. Frontiers in Psychology, 13:841534. doi: 10.3389/fpsyg.2022.841534

https://www.frontiersin.org/articles/10.3389/fpsyg.2022.841534/

\title{
Development of the Japanese Version of
}

the Linguistic Inquiry and Word Count Dictionary 2015 (J-LIWC2015)

\author{
Tasuku Igarashi ${ }^{1}$, Shimpei Okuda ${ }^{2}$, and Kazutoshi Sasahara ${ }^{3}$ \\ ${ }^{1}$ Graduate School of Education and Human Development, Nagoya University \\ ${ }^{2}$ Graduate School of Informatics, Nagoya University \\ ${ }^{3}$ School of Environment and Society, Tokyo Institute of Technology
}

\begin{abstract}
Author Note
Tasuku Igarashi (iD https://orcid.org/0000-0001-9432-4425

Kazutoshi Sasahara if https://orcid.org/0000-0003-2572-0648

Pennebaker Conglomerates, Inc. owns all rights to the J-LIWC2015 dictionary. All royalties given to Tasuku Igarashi and Kazutoshi Sasahara for the commercial use of the J-LIWC2015 dictionary will be donated to Nagoya University and Tokyo Institute of Technology. The research was supported by the Telecommunications Advancement Foundation (Tasuku Igarashi and Kazutoshi Sasahara), JSPS/MEXT KAKENHI Grant Numbers JP17K04314 (Tasuku Igarashi), JP19H04217 (Kazutoshi Sasahara and Tasuku Igarashi), and \#4903, JP17H06383 (Kazutoshi Sasahara) and JST PRESTO Grant Number JPMJPR16D6 (Kazutoshi Sasahara). A preliminary version of the paper was appeared in the Telecommunications Advancement Foundation Research Report (Vol. 33, (https://www.taf.or.jp/files/items/1076/File/\%E4\%BA\%94\%E5\%8D\%81\%E5\%B5\%90\%E7
\end{abstract} 2018, in Japanese) \%A5\%90.pdf). The J-LIWC2015 dictionary can be downloaded from 
http://www.liwc.net/dictionaries/ for the standard LIWC2015 academic license (i.e., noncommercial) users. We thank James W. Pennebaker for his advice at the early stage of the project and Yutaka Fukui, Kengo Furuhashi, Claudia Gherghel, Miho Hayakawa, Jun Ishihara, Machika Kondo, Emiko Omori, Masaki Sugimori, Yasuhiro Taguchi, and Reina Takamatsu for their support in the development of the dictionary.

Correspondence concerning this article should be addressed to Tasuku Igarashi, Graduate School of Education and Human Development, Nagoya University, Furo-cho, Chikusa-ku, Nagoya AICHI 464-8601 Japan. Email: igarashi.tasuku@d.mbox.nagoyau.ac.jp 


\begin{abstract}
The Linguistic Inquiry and Word Count Dictionary 2015 (LIWC2015) is a standard text analysis dictionary that quantifies linguistic/psychometric properties of English words. The development of a Japanese version of the LIWC2015 dictionary (J-LIWC2015) has been expected in the fields of natural language processing and cross-cultural research. This study aims to create J-LIWC2015 through systematic investigations of the original dictionary and Japanese corpora. All words in the LIWC2015 dictionary were initially subjected to human and machine translation into Japanese. After verifying the frequency of use of the words in large corpora, frequent words and phrases that are unique to Japanese were added to the dictionary, followed by re-category assignments by psychologists. The updated dictionary indicated good internal consistency, semantic equivalence with the original LIWC2015 dictionary, and good construct validity in each category. The evidence suggests that the $\mathrm{J}$ LIWC2015 dictionary is a powerful research tool in computational social science to scrutinize psychological processes behind Japanese texts and to promote standardized cross-cultural investigations in combination with the LIWC dictionaries in different languages.
\end{abstract}

Keywords: LIWC, natural language processing, Japanese text analysis, word count approach 


\section{Development of the Japanese Version of the Linguistic Inquiry and Word Count Dictionary (J-LIWC2015)}

Understanding how people feel and think in daily lives is a primary objective in social science. In human society, language is one of the essential tools for thinking and communication to comprehend one's internal states. From personal diaries to public speeches, informal conversations, and posts on social media, the words reflect ruminations and emotions in one's mind and heart. Although the systematic quantitative analysis of textbased data has been a challenging task for social scientists due to its complexity, recent advancements in computational linguistics make it possible to evaluate the psychological meanings of language use.

The Linguistic Inquiry and Word Count (LIWC; pronounced "Luke;" Chung \& Pennebaker, 2012) is a de facto standard analytic framework to quantify psychological constructs embedded in text data. LIWC is composed of computer software and a dictionary file. The software classifies each word in given texts as multiple linguistic/psychological categories based on the words included in the dictionary file (hereafter referred to as "target words") and calculates the proportion of the words in each category to the total number of words in the whole texts. The dictionary file defines target words as a collection of frequently used words, each of which is linked with specific categories, such as positive/negative emotions, cognitive and perceptual processes, and personal and social concerns. Although LIWC can be used for simple sentiment analysis to study affective states such as positive and negative, it is not just a sentiment dictionary but rather a general research tool for inferring more complicated psychological states from texts.

LIWC has been updated constantly since the initial release in the 1990s (Pennebaker \& Francis, 1996). Now, LIWC is applied in various research topics, including the variability of the spread of false news online according to emotional reactions (Vosoughi et al., 2018), analysis on brand/product preferences in news media (Humphreys \& Wang, 2018), mood contagion from charismatic leaders to followers (Bono \& llies, 2006), and language style matching and relationship stability in dyads (Ireland et al., 2011), to name a few (see 
Tausczik \& Pennebaker, 2010 for a review). The LIWC dictionary was initially developed in English and translated in Germany, Simplified Chinese, Traditional Chinese, Spanish, Russian, Arabic, French, Italian, Portuguese, Serbian, Romanian, and Turkish. The availability of localized dictionaries leads LIWC into a gold standard for cross-cultural psycholinguistic analysis. However, LIWC has not been translated into Japanese in a publicly available format.

The LIWC dictionary is constructed and validated in a standardized manner. The target words are collected from large corpora in different communication contexts and screened based on the frequency of use. Then the associations between the target words and the pre-defined psychologically meaningful categories are determined and judged by psychologists. Linguistic categories such as personal pronouns are also allocated to some target words. Each target word corresponds to multiple categories that are organized both horizontally and hierarchically. For example, the target word "beauty" is classified into four categories: "affect" (level 1), "positive emotion" (level 2 under the affect category), "perceptual process" (level 1), and "see" (level 2 under the perceptual process category). Some target words include a wildcard character (“"”) at word endings to match any word that starts with a particular string of characters (e.g., "enjoy”" matches "enjoy," "enjoyable," "enjoyed," and "enjoyment"). The use of the wildcard expands the concise dictionary to cover a broad range of inflected forms of the target words. As of 2021, the newest dictionary was developed in 2015 (LIWC2015) that includes approximately 6,400 target words and more than 70 linguistic/psychological categories.

The current research aims to develop a Japanese version of the LIWC2015 dictionary (J-LIWC2015). Recently, several studies tried to create Japanese versions of the LIWC dictionary (Nasugawa et al., 2016; Shibata, 2018; Tomihira et al., 2018; Yamamoto et al., 2016). However, these studies mainly used a machine translation technique to create the Japanese dictionary from the older versions of the original dictionaries (LIWC2001 and 2007), and the developed dictionaries are not open to the public. The translation of every single target word and its link to psychometric properties were also not thoroughly reviewed 
by experts. So far, no standardized Japanese LIWC dictionary is available for academic researchers.

The construction of the Japanese version of the LIWC dictionary based on the English version is not easy. Linguistic distance (the closeness of language structure) is the farthest between English and Japanese (Chiswick \& Miller, 2005). The complexity of the Japanese language comes from its unique writing system composed of three types of scripts: hiragana (the Japanese cursive syllabary), katakana (the square Japanese syllabary), and kanji (Chinese characters used in Japanese writing). In addition, the word classification system is based on three different origins, wago (or Yamato kotoba; native Japanese words), kango (Chinese-origin words), and gairaigo (words borrowed from foreign, mainly European, language), and their mixture. The multiple origins make the same kanji script have two or more pronunciations called on-yomi (based on kango) and kun-yomi (based on wago), which often represent the same meaning. In addition, the Japanese language has its rich variation of onomatopoeia that describes real sounds (giongo), animal and human sounds (giseigo), and conditions and states (gitaigo) in both hiragana and katakana. Consequently, the average vocabulary size is between 30,000 to 50,000 for native Japanese speakers (undergraduates) (N. Sato et al., 2017), whereas it is around 20,000 for native English speakers (Nation \& Waring, 1997). The process of the development of JLIWC2015 needs to take these complicated issues into account. There is no shortcut.

In this study, we applied the standardized steps to create translated LIWC dictionaries in other languages (Huang et al., 2012; Meier et al., 2019) in careful consideration with the Japanese language characteristics introduced above. The overall procedure involved eight steps (see Figure 1): First, we translated the target words in the LIWC2015 dictionary from English to Japanese (Step 1) and verified and adjusted the associations between the target words and the categories (Step 2). Steps 1 and 2 basically followed the same procedures established in Matsuo, Sasahara, Taguchi, and Karasawa (2019). Then, we examined the word-category associations in large corpora and tested the equivalence between the LIWC2015 and J-LIWC2015 dictionaries (Step 3). We also added 
high-frequency words in Japanese to the dictionary and associated them with the categories (Step 4), followed by the fine-tuning of the category composition (Step 5). We calculated the internal consistency of each category in large corpora (Step 6) and reexamined the correspondence between English and Japanese versions of the dictionary in another data set (Step 7). Finally, we conducted an online essay-writing experiment that manipulated participants' moods to test the construct validity of each category (Step 8).

\section{Steps of Dictionary Development}

\section{Step 1: Initial Translation}

First, KS (computer scientist) and a computer science undergraduate student used the online dictionary Weblio (https://ejie.weblio.jp/) to directly translate all English target words in the LIWC2015 dictionary (hereafter referred to as "source-target words") into Japanese. The source-target words with a wildcard were transformed into multiple English words by the online dictionary search tool OneLook (https://www.onelook.com/) before the processing in Weblio. Every source-target word was translated into single or multiple Japanese words as many as possible. The Balanced Corpus of Contemporary Written Japanese (BCCWJ; https://pj.ninjal.ac.jp/corpus center/bccwi/; 104 million words) and the Tsukuba Web Corpus (TWC; https://tsukubawebcorpus.jp/; 1.1 billion words) were used to check the frequency of use of all translated words. A list of initial candidate words for JLIWC2015 was created based on the translated words included in either of the corpora.

After the machine-translation process, the initial candidate words were manually screened by a group of reviewers, including $\mathrm{TI}$ (social psychologist), KS, and five psychology students. All reviewers either had lived in English-speaking countries or are multilingual. The reviewers evaluated the machine-translated words and fixed and removed unnatural expressions. At this stage, the initial candidate words were standardized to written expressions used in daily lives. If the source-target words represent abstract meanings or do not correspond directly to a single word in Japanese, the reviewers carefully chose translated expressions that reflect the original connotations. Some source-target words that 
were rarely used in Japanese, such as culture-specific words, abbreviations, and proper nouns (e.g., "Yiddish," "DVR," and "Zoloft"), were directly translated ("Yiddish" as it is in Japanese), remained ("DVR" as it is), or changed to the words having more general meaning ("Zoloft" was translated as "antidepressant" in Japanese) in this step. Abbreviated auxiliaries (e.g., "shouldn't") were not translated because no direct translation in single words is available in Japanese. Some source-target words in the informal and netspeak categories (e.g., "prob") and emoticons in the netspeak category (e.g., ":)") were also not translated due to the same reason.

Wildcards were added for three cases: (1) compound words that include hiragana, katakana, and/or kanji as a source of meaning, followed by other characters (e.g., a kanji “飲” means “drinking;” “飲食” means “drinking and eating” and “飲酒” means "drinking alcohol;" therefore, "飲”” captures all expressions), (2) inflected forms of words (changed in their endings) including verbs (conjugation) and adjectives (declension) (e.g., “教える” means "teach" as a verb; and it inflects as “教えて,” “教えた,” “教えろ,” and so forth according to the context; therefore, “教元”" captures all expressions), and (3) nominalized and adnominalized forms of words from adjectives (e.g., “小さい” means "small” as an adjective; and “小ささ” means "smallness” as a noun; and “小さな” means "small” as adnominal; therefore, “小さ*” captures all expressions) ${ }^{1}$. LIWC processes target words with wildcards by priority, so wildcards were used only if the same characters do not have different meanings in different forms of words ${ }^{2}$.

\footnotetext{
${ }^{1}$ Adjectives in English correspond to adjectival verbs, adjectival nouns, and adnominals in Japanese.

2 Dictionaries used for translations in Step 1 are listed in Section 1 in Supplementary Materials.
} 
Unlike English, Japanese does not use spaces to separate words. Preprocessing texts by word segmentation is essential to determine word units in LIWC. We used the de facto standard tool for morphological analysis MeCab Version $0.996^{3}$ (Kudo et al., 2004) with IPA Dictionary (IPADIC) Version 2.7.0 (Asahara \& Matsumoto, 2003) for segmenting texts into words and attaching part of speech for each word ${ }^{4}$. During the preprocessing, some single initial words were divided into two or more morphemes (e.g., “億万長者” (billionaire) is segmented as “億” (billion), ”万” (ten thousand), and “長者” (rich person)). We created a user dictionary for MeCab to handle these compound words as single word units and confirmed that all initial candidate words were treated as single morphemes. The user dictionary is available from https://github.com/tasukuigarashi/j-liwc2015. Other preprocessing schemes, such as converting fullwidth characters to halfwidth characters (e.g., numbers and alphabet letters), are introduced in a script that can be downloaded from the link.

\section{Step 2: Initial Category Verification}

The reviewers checked the correspondence between the initial candidate words translated into Japanese and the categories attached to their source-target words in English. Linguistic categories of J-LIWC2015 are slightly different from those of LIWC2015 due to the substantial differences in grammar between Japanese and English. Therefore, J-LIWC2015 does not include the article, propositions, comparisons, and time orientations categories. Articles and propositions are not used in Japanese, and the comparative degrees and the tenses (time orientations) are expressed as adverbs and auxiliary verbs, respectively. If the same initial candidate words correspond to two or more source-target words that are linked to different categories, all relevant categories were attached to the single translated

\footnotetext{
3 Translation of the MeCab documentation to English is available at https://github.com/jordwest/mecab-docs-en.

${ }^{4} \mathrm{MeCab}$ can be used with other dictionaries like UniDic (https://unidic.ninjal.ac.jp/en/) and NEologd (T. Sato et al., 2017). However, the J-LIWC2015 dictionary is optimized for IPADIC. We cannot guarantee the compatibility of the findings if researchers use other dictionaries in MeCab for morphological analysis.
} 
expressions (e.g., “利益” means both "benefit" (linked to the reward category) and "profit" (linked to the reward and work categories) in Japanese. Therefore, the translated word was linked to both the reward and work categories). Categories linked to single source-target words were attached separately to two or more initial candidate words if single translated words cannot cover all the categories (e.g., the source-target word "foundation*" is linked to the space and work categories, but no single Japanese word can represent both meanings. In this case, the translation is distinguished between “土台” for the former and “協会” for the latter category). The verbs category was attached to the limited number of the initial candidate words because a lot of verbs in Japanese are compound words of nouns and a specific auxiliary verb ”する” (doing) and its inflections (e.g., “信頼” means "trust” as a noun and “信頼する” as a verb).

\section{Step 3: Initial Equivalence Check between Japanese and English dictionaries}

After the initial translation and categorization, we compared the numbers of words allocated to each category in the English and Japanese versions of dictionaries. A research team in a Japanese linguistic technology company specialized in national language processing compared the frequency of occurrence of the source-target words in English and the initial candidate words in Japanese (translated in Steps 1 and 2) in five large multilingual corpora, the English-Japanese Translation Alignment Data (Utiyama \& Takahashi, 2003; 112,502 sentences), OpenSubtitles (http://www.opensubtitles.org/; 2,082,927 sentences), Japanese-English Subtitle Corpus (JESC; Pryzant et al., 2018; 2,801,388 sentences), JEC Basic Sentence Data (http://nlp.ist.i.kyoto-u.ac.jp/EN/?JEC\%20Basic\%20Sentence\%20Data; 5,304 sentences), and JParaCrawl (Morishita et al., 2020; 2,309,630 words) all of which include both English and Japanese texts for the same contents.

If large discrepancies in the numbers of words in particular categories were found between the English and Japanese dictionaries, synonyms were searched through 
Japanese WordNet (Isahara et al., 2008) and added to the categories until the discrepancies were resolved. Many function words with inflections were added in this step. In the religion and netspeak categories, substantial discrepancies were observed between the two dictionaries. To fill the gap, the research team added new Japanese words that are not included in LIWC2015 but represent the meaning of the categories (e.g., “仏教” ("Buddhism") and "2ch" (the largest internet forum in Japan like Reddit)) as many as possible by searching relevant literature and the web.

\section{Step 4: Word Frequency Check}

In this step, KS and SO (a computer science graduate student) checked the frequency of the words in the current version of the dictionary from large Japanese corpora, including BCCWJ, TWC, the National Institute for Japanese Language and Linguistics Web Japanese Corpus (NWJC; Asahara et al., 2014; 25 billion words), and the UniDic version of the Corpus of Spontaneous Japanese (CSJ; Watanabe et al., 2015; 7.5 million words from transcriptions of speech). Due to the low word frequency in the netspeak category in these corpora, random samples of Nicovideo Comment Etc. Data (DWANGO Co., Ltd., 2018; 17,349 videos) and Twitter data (scraped by the authors; 569,760 words; https://twitter.com) were used to examine the frequency of the netspeak words included in the current version of the dictionary. The words having wildcards were extracted to multiple words by prefix searches in the corpora.

Word frequencies of each corpus were converted to normalized frequency scores based on frequencies per million words (PMW). Low frequent words (PMW $<1$ in all corpora) were removed from the dictionary. Words frequently used in the corpora but not listed in the translation-based dictionary were screened and added according to their relevance to each category. During the process of word addition, three new linguistic categories were created to include function words that cannot be classified in the existing LIWC categories: case particles (particles placed after the nouns, such as “から” (“from”)), 
adjective verbs (a modified form of nouns that work like adjectives by adding a specific auxiliary verb “な” at the end of the nouns, such as “贅沢な” (“luxury”)), and pronoun adjectival (adjectival words that are not categorized as either adjectives or adjectival verbs, such as “同じ” (“equivalent”)).

\section{Step 5: Second Category Verification}

After compiling the dictionary based on word frequency, all words were sorted on a category-by-category basis. Then a category evaluation team composed of $\mathrm{Tl}$ and three graduate students (majoring in social psychology, developmental psychology, and cognitive psychology) thoroughly checked if each Japanese word accurately reflects the overall meaning of the category in the same way as in the English dictionary. Each member of the team evaluated the word-category correspondence individually. The team discussed the judgments and recategorized them if necessary for the words that were judged as not fitted for a given category. Following the standard procedure to develop psychological assessment scales, the correspondence between a psychological construct behind each category and the words in that category were carefully examined. For example, all words in the affiliation and achievement categories were checked if they were generally fitted for one's internal states and behavior derived from the affiliation and achievement motivation theory (Atkinson, 1964; Hill, 1987). The team also amended minor errors in the dictionary, such as typos, in this step.

\section{Step 6: Internal Consistency Check}

From a psychometric perspective, a reliable psychological measure needs to represent target psychological characteristics consistently. According to Pennebaker et al. (2015), if an LIWC-like dictionary-based measure properly captures the psychological

\footnotetext{
5 In MeCab, auxiliary verbs are divided into nouns and the auxiliary verb "な." Considering that the English version of LIWC2015 does not include a category for nouns, we implemented the adjective verb category for the noun part of the words.
} 
aspects of someone who produces a text, the text would contain multiple words assorted in the same psychological category in the dictionary. For example, if a person writes a diary in Japanese about their positive experience, multiple words in the positive emotions category in J-LIWC2015, such as “楽し*” (“fun”) and “素晴らし*” (“wonderful”), would occur in the same text. The expressive pattern is regarded as internally consistent to the extent that the person's positive emotions are consistently high across the text. Based on the idea, the internal consistency of each category in J-LIWC2015 was tested based on Pennebaker et al.'s (2015) procedure explained below.

In this step, $\mathrm{TI}, \mathrm{KS}$, and SO were engaged in the calculation of internal consistency of each of the categories by using ten corpora including more than 800 million words in total: Japanese novels and essays registered in Aozora Bunko (https://www.aozora.gr.jp/), the minutes of plenary sessions and budget committees of the upper and lower and houses of the National Diet of Japan (https://kokkai.ndl.go.jp/), Livedoor News Corpus (https://www.rondhuit.com/download.html\#ldcc), Nagoya University Conversation Corpus (NUCC; Fujimura et al., 2012), Nicovideo Comment Etc. Data, the Open 2channel Dialogue Corpus (Inaba, 2019), the Japanese subtitles of TED Talks (https://www.ted.com/), and the Twitter data used in Step 4. The Aozora Bunko and National Diet minutes corpora are provided by the Himawari full-text retrieval system (https://www2.ninjal.ac.jp//rc/index.php?himawari). The total words and texts (a minimum unit of analysis that includes the same topic) and relative word counts, or the proportion of dictionary words use to the total number of words in each text, were computed in each corpus (see Table S1 in Supplementary Materials).

Cronbach's alpha coefficient was then calculated for each category at each corpus and averaged across the corpora (i.e., uncorrected alpha). The analysis regarded texts as responses, words as items, categories as factors, and the proportion of word use as item scores. One caveat is that Cronbach's alpha coefficient calculation is not perfectly suitable when limited expressions are used in each free-descriptive text and when limited topics are 
covered at each corpus. In both cases, uncorrected alphas tend to be underestimated. The Spearman-Brown prediction formula was employed to adjust the bias under the assumption that the averaged alpha is observed in the ten corpora (i.e., corrected alpha) (Pennebaker et al., 2015).

The corrected alphas generally show high internal consistency, with some exceptions. The uncorrected alpha was generally small in the personal pronouns category and its subcategories. The netspeak category also showed low internal consistency, probably due to the difficulty of allocating diverse expressions commonly used on the internet across different platforms and generations into a single category. In response to these results, very-low and very-high frequent words were moved to different categories or removed from the dictionary to increase internal consistency. Although the alphas remained relatively low in the personal pronouns category even after the amendments, there would be several reasons accounting for the result. Using pronouns in Japanese is not mandatory in a sentence and is often avoided to reduce redundancy. In addition, the limited number of pronouns, such as “私” (I), is frequently used in Japanese to refer to someone or something in the context of conversations ${ }^{6}$. Therefore, we conclude that having low alphas in these categories is not problematic in Japanese.

The final findings are presented in Table S2 in Supplementary Materials. The number of words removed in this step was very small ( 41 words; $0.4 \%$ of the dictionary words). After the amendments, we compiled the final version of the J-LIWC2015 dictionary, which includes 11,600 words and 69 categories (see Table 1).

\section{Step 7: Second Equivalence Check between Japanese and English dictionaries}

In this step, TI verified the equivalence between the final versions of J-LIWC2015 and LIWC2015. Two corpora were served for the analysis: TED Talks (subtitles available in

\footnotetext{
${ }^{6}$ Negative alpha coefficients in the personal pronouns category are found only in the conversation corpora (National Diet Minutes and NUCC).
} 
both Japanese and English; 4,509 talks) and the Bible (the Old and New Testaments in the Colloquial Japanese Version and the Revised Standard Version in English; 1,372 chapters; http://www.babelbible.net/pdf/pdfmari.cgi?mode=right). Each category's relative word counts were compared between Japanese and English texts in each corpus and the combined corpora. We computed Hedges' $g$ (i.e., unbiased Cohen's $d$ for two-sample $t$-test) and Pearson's correlation coefficients $(r)$ as equivalence indices of the Japanese and English versions of the dictionary. The similar the two versions are, the larger $r$ s are, and the smaller gs are (rs are also expected to be positive). Table S3 in Supplementary Materials shows the results.

Overall, linguistic and non-linguistic categories did not show a large discrepancy between J-LIWC2015 and LIWC2015 in the combined corpora. In the verbs category, a substantial discrepancy between J-LIWC2015 and LIWC2015 was observed. The finding is consistent with our dictionary editing polity introduced in Step 2 . The space category showed a relatively larger gap than the other categories probably because the English version includes high frequent prepositions in the category, such as "on," "off," and "over," that are part of idioms (e.g., "where are you off to?") and do not directly correspond to single Japanese words. The frequency of social category in J-LIWC2015 was also a bit lower than that in LIWC2015. This is probably because personal pronouns are allocated to this category in LIWC2015, whereas they are not frequently used in Japanese.

The relatively low correlation coefficients were also found in the subcategories of the informal language category. This would be because some proper nouns (e.g., "Ba'al-ha'nan" and "Josi'ah," both of which are segmented by "'” (apostrophe) and "-" (hyphen) in the LIWC2015 software) in the Bible correspond to the words of the netspeak (e.g., "ha") and assent (e.g., "ah") categories in LIWC2015, but not in J-LIWC2015. Similarly, some proper nouns (e.g., “アッスリヤ” (“Assyria”)) correspond to the words of the nonfluencies category 
(e.g., “アッ*”) in J-LIWC2015, but not in LIWC2015. Note that this is not a specific issue of the dictionary equivalence but a general issue of a word-count approach.

\section{Step 8: Construct Validity Check}

At the final step of the dictionary construction, we conducted an online experiment to confirm if participants' emotional state induced by an essay-writing task corresponded to the results of natural language processing by J-LIWC2015 ${ }^{7}$. In this step, we set the threshold for significance tests at $p<.005$ (Benjamin et al., 2018) to minimize Type I error.

\section{Participants}

Data from an online survey about daily experience and personality (Igarashi, 2019, Sample 2) was used in the study ${ }^{8}$. A total of 522 Japanese crowdsourcing workers recruited via Lancers (https://www.lancers.jp) completed an online questionnaire. The questionnaire was created on Qualtrics and took 25.5 minutes $(S D=24.0)$ on average to complete. Each participant received 410 Japanese Yen (approximately \$4) for their remuneration. We excluded 22 answers from the data, including five participants who did not agree to write an essay, two participants whose essays were nonsense, and 15 participants who did not agree to use their answers for the study. Finally, we analyzed the data from 500 participants (305 females and 195 males, $\left.M_{\text {age }}=37.9, S D_{\text {age }}=9.85\right)^{9}$.

\section{Materials and procedure}

We induced participants' emotional state by an essay-writing task (Oikawa \& Oikawa, 2012). At the beginning of the survey, participants were asked if they agreed to write an essay for one of the following topics: a positive experience (the positive emotion condition; $n$

\footnotetext{
${ }^{7}$ The study was approved by the Ethical Review Board of the first author's institution.

8 In the survey, participants were asked to report demographic information (gender, age, academic background, and occupation), to write an essay after emotion induction manipulation, and to report emotional states, Ioneliness, and Big Five personality factors. Igarashi (2019, Sample 2) used the demographic and psychological variables to verify factor structure and construct validity of a loneliness scale. The current study reports the result of essay content analysis based on J-LIWC2015, which is not included in Igarashi (2019, Sample 2).

${ }^{9}$ Sensitivity power analysis in G*Power3 (Faul et al., 2007) for one-way ANOVA (fixed effects, omnibus, three groups) shows that the effect size $(f)$ of the current study $(N=500)$ is 0.178 with a (error probability) $=0.005$ and $\beta$ (power) $=0.80$. This indicates that the current sample size is sufficient to detect small effects.
} 
$=164$ ), a negative experience (the negative emotion condition; $n=179$ ), or an ordinary experience (the control condition; $n=157$ ) in recent days. Participants who agreed to write an essay did it for the given topic more than 200 letters in Japanese. During the writing, participants were asked to be expressive by referring to their emotional states in the experience.

Upon completion, participants answered the pleasantness of the experience ( 1 item; "How was the experience for you?") on a 6-point Likert scale ("1: very negative" to "6: very positive") and the impact of the experience ( 2 items; "I often remember the experience" and "the experience was important for me.") on a 6-point Likert scale ("1: strongly disagree" to "6: strongly agree") as manipulation checks. Participants also reported their emotional states by the Japanese version of the Positive and Negative Affect Schedule (PANAS) (A. Sato \& Yasuda, 2001) (16 items; 6-point Likert scale), followed by Big-Five personality factors (Namikawa et al., 2012) (29 items; 7-point Likert scale).

\section{Content analysis}

In this section, we examined if there were substantial differences in word use in categories among two or more combinations of the three (positive emotion, negative emotion, and control) conditions. The details of statistical analysis (manipulation check and multiple comparison tests) are reported in Section 2 in Supplementary Materials. On average, the dictionary words covered $78.1 \%(S D=4.41)$ of the words that appeared in the essays. Figure 2 presents the descriptive information of the proportion of word occurrence (and word counts) in linguistic categories (function words and other grammars) in each condition; and Figure 3 presents the average proportions of word occurrence in nonlinguistic categories in each condition, each followed by multiple comparison tests across the conditions.

Overall, the contents of the essays corresponded to the induced emotional states. Participants in the control condition tended to write about non-social, leisure-related 
episodes at home, including something related to ingestions (e.g., watching TV alone in the living room while eating snacks). In contrast, participants in the positive emotion condition tended to write about positive, social, drive-based, and leisure-related episodes (e.g., remembering the enjoyment of a visit to a museum with family). Participants in the negative emotion condition tended to write about negative (especially anger and sad), social, drivebased but death-related and less healthy episodes (e.g., having tiredness and hopelessness because of serious trouble with a colleague). The tendency of word usage in the linguistic and cognitive processes categories suggests that the episodes in these conditions were described as subjective and explanatory (i.e., frequent use of personal singular pronouns and conjunctions) with less specific and more contrasting expressions. Neither total word counts nor the proportion of dictionary words to the overall word counts differed across the conditions. The patterns indicate that the J-LIWC2015 dictionary has sufficient construct validity to capture various psychological characteristics reflected in verbal expressions observed in different emotional states.

\section{Discussion}

The goal of the current study is to develop the Japanese version of the LIWC2015 dictionary. Through a series of systematic analyses, the J-LIWC2015 dictionary includes both the translated words from the original English version and the frequent words adopted from large Japanese corpora with sufficient internal consistency across various linguistic and psychological categories. The overall equivalence between the J-LIWC2015 and LIWC2015 dictionaries was confirmed by comparing Japanese and English transcripts and texts. Construct validity of J-LIWC2015 was also endorsed by the content analysis of the essay writings in the emotion induction task. The evidence suggests that J-LIWC2015 is a powerful research tool for social scientists to scrutinize psychometric aspects embedded in Japanese texts.

J-LIWC2015 has great potential for future research in the era of large-scale social data analytics. Researchers can use the dictionary to analyze one's psychological states 
from basic single-person pronouns to complicated psychological processes reflected in several forms of voluminous Japanese texts, such as posts on social networking sites, voice chat logs in online gaming, audio transcripts of interviews and videos, meeting minutes, and so forth. For example, Sasahara, Okuda, and Igarashi (2021) analyzed Twitter posts by JLIWC2015 (a beta version) to examine the patterns of changes in consumers' reactions toward the resell of essential goods (e.g., face masks and hand sanitizers) in Japan during the initial stage of the COVID-19 pandemic from March to August 2020. The longitudinal research found that the peaks of drive-related category word use on Twitter corresponded to the propagation of news related to the reselling, such as the power category and legal sanctions against face mask reselling for profits and the rewards category and criticisms on making excessive profits from the crisis. These findings suggest the utility of validated textbased analytic tools for gauging psychological trends in public opinion on the internet.

The equivalence between the J-LIWC2015 and LIWC2015 dictionaries also facilitates a content analysis of texts written in the same context by different language speakers. For example, a cross-cultural study (Lopez et al., 2019) used LIWC2007 to analyze the content of Twitter posts in 2017 with the \#MeToo hashtag (a social media hashtag used to confess and share experiences of sexual harassment and other forms of victimization against women) in French and English. The findings revealed that French tweets included more aggressive (swear) expressions than English tweets. Now the same research design can be applied to comparative analysis of Japanese and English texts. Meanwhile, recent research (Windsor et al., 2019) claims the universality of English-based LIWC2015 to analyze machine-translated texts (United Nations documents) from several non-English source languages (not including Japanese) to English. Nonetheless, the approach may miss highfrequent words observed only in source languages. At least for the present moment, the coverage of this approach would be limited to texts that do not include informal words and culture-specific expressions. 
Although the current version of the J-LIWC205 dictionary satisfies the equivalence with the English version, one substantial difference between the two is that linguistic categories such as verbs are not actively assigned to the dictionary words in J-LIWC2015. Also, it is often the case in Japanese that the same word can be assigned to a different part of speech according to the contexts of the word use. More broadly, proper nouns and nondictionary words might be mishandled in both J-LIWC2015 and LIWC2015, as the names in the Bible were regarded as part of informal language in Step 6. All issues mentioned above stem from the fact that the LIWC2015 software does not use context information and word co-occurrence patterns for word category classification.

If researchers need more detailed linguistic information of text data in consideration with contexts, we suggest using MeCab with IPADIC in postprocessing in addition to preprocessing. Since its release in 2006, MeCab with IPADIC has been widely used for natural language processing in Japanese. At the preprocessing stage of the application of JLIWC2015, MeCab/IPADIC is used for morphological analysis of a Japanese text. In addition, the software can provide part of speech information for every word in the text estimated from word occurrence and conjunction costs (the likelihoods of two words to occur and linked calculated based on the part of speech information of frequent words in IPADIC). Upon necessity, researchers can add linguistic category information of the entire text by combining the result of MeCab/IPADIC analysis on the part of speech information with the output of the LIWC2015 software.

Figure 4 introduces a general framework for the natural language processing of Japanese texts by the J-LIWC2015 dictionary, MeCab/IPADIC, and the LIWC2015 software. The framework contains the preprocessing, main analysis, and postprocessing stages. At the preprocessing stage, researchers convert Japanese texts to be readable in LIWC2015 software and conduct morphological and part of speech analyses in MeCab/IPADIC (researchers can also utilize part of speech information of each word for filtering nondictionary proper nouns that may be mislabeled in J-LIWC2015, although this is beyond the 
scope of the current study). At the main analysis stage, researchers use the output of the morphological analysis in the LIWC2015 software for linguistic/psychological category assignments based on the J-LIWC2015 dictionary. Researchers can finish the analysis at this stage and use the output for extensive analysis. If researchers need a more detailed part of speech information, they can proceed to the postprocessing stage and combine the output of linguistic/psychological categories (obtained at the main analysis stage) with the output of the part of speech information (obtained at the preprocessing stage) for extensive analysis. Postprocessing is optional and dependent on the research purpose. If researchers think integrating the outputs from the J-LIWC2015 dictionary and MeCab/IPADIC can get the best of both worlds, we recommend adopting this option. Table S5 in Supplementary Materials presents a case of analysis of postprocessing, showing that MeCab/IPADIC captures more words in the verbs, adverbs, and auxiliary verbs categories than the J-LIWC2015 dictionary. Sample scripts for postprocessing can be downloaded from https://github.com/tasukuigarashi/j-liwc2015.

It is also a matter of concern in Japanese text analysis to handle different expressions efficiently; this is still an open issue in natural language processing. The diversity of Japanese scripts leads to the emergence of orthographical variants. For example, the combination of the scripts (e.g., “行う” (“do”) can be written as “行なう” and “お こなう”), the use of dialects (e.g., “疲れた” ("tired”) is spoken as“こわい” in Hokkaido dialect), and the use of a traditional form of kanji scripts (e.g., “学校” (“school”) was used to be written as “學校”) result in different expressions of the same words and meanings. We try to resolve the issue by including different expressions of the same words in the dictionary, but the current version of J-LIWC2015 does not systematically handle orthographical variants (e.g., the dictionary does not include traditional forms of kanji scripts). The conversion of the variants to standard expressions at the preprocessing stage will help to increase the coverage rates of the dictionary words. 
The LIWC2015 software takes a word count approach based on the fixed lexicon without considering the contexts of word use. Meanwhile, recent research has reported a potential advantage of advanced machine-learning algorithms, such as the Bidirectional Encoder Representations and Transformations (BERT; Devlin et al., 2018) and the Generative Pre-trained Transformer 3 (GPT-3; Brown et al., 2020), over the traditional word count approach in natural language processing (Lake \& Murphy, 2021). For example, when the effectiveness of linguistic/psychological category information assigned by BERT and LIWC2015 (in Germany) was compared to predict positive and negative communication behavior in dyadic conversations, BERT was likely to outperform LIWC2015 (Biggiogera et al., 2021). There is no doubt that applying data-driven machine learning technology in this field has a promising future. From a psychology perspective, however, embodiment is essential for humans to perceive the social world and represent meanings of words and symbols in the mind, but the current distributional semantic approaches might not formulate the somatic aspects as humans do. Also, one of the biggest drawbacks is the availability of training data; neural language models such as BERT need large-scale "labelled" data for training and fine-tuning, but such data are not often easily available in social science research. Furthermore, we should be careful not only in its performance but also in its transparency and accountability specifications in data processing (Felzmann et al., 2019).

To conclude, the J-LIWC2015 dictionary provides a better understanding of the psychometric properties of Japanese texts. The dictionary is expected to act as a significant bridge between quantitative and qualitative research in Japanese that allows researchers to gain multifaceted and deep insights into the data. We hope that the dictionary will be used in a wide range of fields of Japanese text analysis and foster further innovations in social science. 


\section{References}

Asahara, M., Maekawa, K., Imada, M., Kato, S., \& Konishi, H. (2014). Archiving and analysing techniques of the ultra-large-scale web-based corpus project of NINJAL, Japan. Alexandria, 25(1-2), 129-148. https://doi.org/10.7227/ALX.0024

Asahara, M., \& Matsumoto, Y. (2003). ipadic version 2.7.0 user's manual. https://osdn.net/projects/naist-jdic/docs/ipadic-2.7.0-manual-en.pdf/en/1/ipadic-2.7.0manual-en.pdf.pdf

Atkinson, J. W. (1964). An introduction to motivation. Van Nostrand.

Benjamin, D. J., Berger, J. O., Johannesson, M., Nosek, B. A., Wagenmakers, E.-J., Berk, R., Bollen, K. A., Brembs, B., Brown, L., Camerer, C., Cesarini, D., Chambers, C. D., Clyde, M., Cook, T. D., De Boeck, P., Dienes, Z., Dreber, A., Easwaran, K., Efferson, C., ... Johnson, V. E. (2018). Redefine statistical significance. Nature Human Behaviour, 2(1), 6-10. https://doi.org/10.1038/s41562-017-0189-z

Biggiogera, J., Boateng, G., Hilpert, P., Vowels, M., Bodenmann, G., Neysari, M., Nussbeck, F., \& Kowatsch, T. (2021). BERT meets LIWC: Exploring state-of-the-art language models for predicting communication behavior in couples' conflict interactions. In arXiv [Cs.CL]. arXiv. http://arxiv.org/abs/2106.01536

Bono, J. E., \& llies, R. (2006). Charisma, positive emotions and mood contagion. The Leadership Quarterly, 17(4), 317-334. https://doi.org/10.1016/j.leaqua.2006.04.008

Brown, T. B., Mann, B., Ryder, N., Subbiah, M., Kaplan, J., Dhariwal, P., Neelakantan, A., Shyam, P., Sastry, G., Askell, A., Agarwal, S., Herbert-Voss, A., Krueger, G., Henighan, T., Child, R., Ramesh, A., Ziegler, D. M., Wu, J., Winter, C., ... Amodei, D. (2020). Language models are few-shot learners. In arXiv [Cs.CL]. arXiv. http://arxiv.org/abs/2005.14165

Chiswick, B. R., \& Miller, P. W. (2005). Linguistic distance: A quantitative measure of the distance between English and other languages. Journal of Multilingual and Multicultural Development, 26(1), 1-11. https://doi.org/10.1080/14790710508668395 
Chung, C. K., \& Pennebaker, J. W. (2012). Linguistic Inquiry and Word Count (LIWC): Pronounced "Luke," ... and other useful facts. In P. M. McCarthy \& C. BoonthumDenecke (Eds.), Applied natural language processing: Identification, investigation and resolution (pp. 206-229). IGI Global. https://doi.org/10.4018/978-1-60960-7418.ch012

Devlin, J., Chang, M.-W., Lee, K., \& Toutanova, K. (2018). BERT: Pre-training of deep bidirectional transformers for language understanding. In arXiv [Cs.CL]. arXiv. http://arxiv.org/abs/1810.04805

DWANGO Co., Ltd. (2018). Nicovideo Comment etc. data [Data set]. Informatics Research Data Repository, National Institute of informatics. https://doi.org/10.32130/idr.3.1 Faul, F., Erdfelder, E., Lang, A.-G., \& Buchner, A. (2007). G*Power 3: A flexible statistical power analysis program for the social, behavioral, and biomedical sciences. Behavior Research Methods, 39(2), 175-191. https://doi.org/10.3758/bf03193146

Felzmann, H., Villaronga, E. F., Lutz, C., \& Tamò-Larrieux, A. (2019). Transparency you can trust: Transparency requirements for artificial intelligence between legal norms and contextual concerns. Big Data \& Society, 6(1), 2053951719860542. https://doi.org/10.1177/2053951719860542

Fujimura, I., Chiba, S., \& Ohso, M. (2012). Lexical and grammatical features of spoken and written Japanese in contrast: Exploring a lexical profiling approach to comparing spoken and written corpora. Proceedings of the VIIth GSCP International Conference. Speech and Corpora, 393-398. http://www.letras.ufmg.br/padrao_cms/documentos/eventos/gscp2012/73.pdf

Hill, C. A. (1987). Affiliation motivation: People who need people... but in different ways. Journal of Personality and Social Psychology, 52(5), 1008-1018. https://doi.org/10.1037/0022-3514.52.5.1008

Huang, C.-L., Chung, C. K., Hui, N., Lin, Y.-C., Seih, Y.-T., Lam, B. C. P., Chen, W.-C., Bond, M. H., \& Pennebaker, J. W. (2012). The development of the Chinese linguistic inquiry and word count dictionary. Chinese Journal of Psychology, 54(2), 185-201. 
Humphreys, A., \& Wang, R. J.-H. (2018). Automated text analysis for consumer research. The Journal of Consumer Research, 44(6), 1274-1306. https://doi.org/10.1093/jcr/ucx104 Igarashi, T. (2019). Development of the Japanese version of the Three-Item Loneliness Scale. BMC Psychology, 7:20, 1-8. https://doi.org/10.1186/s40359-019-0285-0 Inaba, M. (2019). A example-based dialogue system using the Open 2channel Dialogue Corpus. The 87th Special Interest Group on Spoken Language Understanding and Dialogue Processing (JSAI-SLUD), 129-132.

Ireland, M. E., Slatcher, R. B., Eastwick, P. W., Scissors, L. E., Finkel, E. J., \& Pennebaker, J. W. (2011). Language style matching predicts relationship initiation and stability. Psychological Science, 22(1), 39-44. https://doi.org/10.1177/0956797610392928 Isahara, H., Bond, F., Uchimoto, K., Utiyama, M., \& Kanzaki, K. (2008). Development of the Japanese WordNet. LREC. http://www.cs.brandeis.edu/ marc/misc/proceedings//rec-2008/pdf/609_paper.pdf Kudo, T., Yamamoto, K., \& Matsumoto, Y. (2004). Applying conditional random fields to Japanese morphologiaical analysis. IPSJ SIG Notes, 2004(47), 89-96. https://ci.nii.ac.jp/naid/110002911717/en/

Lake, B. M., \& Murphy, G. L. (2021). Word meaning in minds and machines. Psychological Review. https://doi.org/10.1037/rev0000297

Lopez, I., Quillivic, R., Evans, H., \& Arriaga, R. I. (2019). Denouncing sexual violence: A cross-language and cross-cultural analysis of \#MeToo and \#BalanceTonPorc. Human-Computer Interaction - INTERACT 2019, 733-743. https://doi.org/10.1007/978-3-030-29384-0_44

Matsuo, A., Sasahara, K., Taguchi, Y., \& Karasawa, M. (2019). Development and validation of the Japanese Moral Foundations Dictionary. PloS One, 14(3), e0213343. https://doi.org/10.1371/journal.pone.0213343 
Meier, T., Boyd, R. L., Pennebaker, J. W., Mehl, M. R., Martin, M., Wolf, M., \& Horn, A. B. (2019). "LIWC auf Deutsch": The development, psychometrics, and introduction of DE-LIWC2015. PsyArXiv. https://doi.org/10.17605/OSF.IO/TFQZC

Morishita, M., Suzuki, J., \& Nagata, M. (2020). JParaCrawl: A large scale web-based English-Japanese parallel corpus. Proceedings of the 12th Language Resources and Evaluation Conference, 3603-3609. https://www.aclweb.org/anthology/2020.Irec-1.443/

Namikawa, T., Tani, I., Wakita, T., Kumagai, R., Nakane, A., \& Noguchi, H. (2012). Development of a short form of the Japanese Big-Five Scale, and a test of its reliability and validity. Shinrigaku Kenkyu: The Japanese Journal of Psychology, 83(2), 91-99. https://doi.org/10.4992/jjpsy.83.91

Nasugawa, T., Kamijo, K., Yamamoto, M., \& Kitamura, H. (2016). Research on linguistic characteristics for personality estimation in Japanese writing. Proceedings of the 22nd Annual Meeting of the Association for Natural Language Processing, 11811184.

Nation, P., \& Waring, R. (1997). Vocabulary size, text coverage and word lists. In N. Schmitt \& M. McCarthy (Eds.), Vocabulary: Description, acquisition and pedagogy (pp. 619). Cambridge University Press.

Oikawa, H., \& Oikawa, M. (2012). Effects of emotional suppression on explicit and implicit mood. Japanese Journal of Social Psychology, 28(1), 24-31. https://doi.org/10.14966/jssp.KJ00008195840

Pennebaker, J. W., Boyd, R. L., Jordan, K., \& Blackburn, K. (2015). The development and psychometric properties of LIWC2015. http://hdl.handle.net/2152/31333

Pennebaker, J. W., \& Francis, M. E. (1996). Cognitive, emotional, and language processes in disclosure. Cognition and Emotion, 10(6), 601-626.

https://doi.org/10.1080/026999396380079 
Pryzant, R., Chung, Y., Jurafsky, D., \& Britz, D. (2018). JESC: Japanese-English Subtitle Corpus. Language Resources and Evaluation Conference (LREC). https://nlp.stanford.edu/projects/jesc/

Sasahara, K., Okuda, S., \& Igarashi, T. (2021). Text mining approach to quantify consumer psychology and behavior in COVID-19 pandemic. Proceedings of the Annual Conference of JSAI, JSAI2021, 1D3OS3b04-1D3OS3b04. https://doi.org/10.11517/pjsai.JSAl2021.0_1D3OS3b04

Sato, A., \& Yasuda, A. (2001). Development of the Japanese version of Positive and Negative Affect Schedule (PANAS) scales. The Japanese Journal of Personality, 9(2), 138-139. https://ci.nii.ac.jp/naid/110001223687

Sato, N., Tajima, M., Hashimoto, M., Matsushita, T., \& Sasao, Y. (2017). Development of a Japanese vocabulary size test based on frequency of use: an attempt to measure up to 50,000 word level. Chiba University International Liberal Studies Research, 1, 1525. https://doi.org/10.20776/S24326291-1-P15

Sato, T., Hashimoto, T., \& Okumura, M. (2017). Implementation of a word segmentation dictionary called mecab-ipadic-NEologd and study on how to use it effectively for information retrieval (in Japanese). Proceedings of the Twenty-Three Annual Meeting of the Association for Natural Language Processing, NLP2017-B6-1.

Shibata, D. (2018). Screening of dementia through natural language processing [Master's thesis in Engineering, Nara Institute of Science and Technology]. https://library.naist.jp/mylimedio/dllimedio/show.cgi?bookid=100229953

Tausczik, Y. R., \& Pennebaker, J. W. (2010). The psychological meaning of words: LIWC and computerized text analysis methods. Journal of Language and Social Psychology, 29(1), 24-54. https://doi.org/10.1177/0261927x09351676

Tomihira, J., Yamashita, A., \& Matsubayashi, M. (2018). User information estimation by LIWC and its application to SNS data. Proceedings of the 80th National Convention of the Information Processing Society of Japan, 539-540. 
Utiyama, M., \& Takahashi, M. (2003). English-Japanese Translation Alignment Data. https://www2.nict.go.jp/astrec-att/member/mutiyama/align/index.html

Vosoughi, S., Roy, D., \& Aral, S. (2018). The spread of true and false news online. Science, 359(6380), 1146-1151. https://doi.org/10.1126/science.aap9559

Watanabe, R., Tanaka, Y., \& Koiso, H. (2015). Constructing the UniDic version of the morphological information of corpus of spontaneous Japanese. Proceeding of the 8th Japanese Corpus Linguistics Workshop, 279-288.

Windsor, L. C., Cupit, J. G., \& Windsor, A. J. (2019). Automated content analysis across six languages. PloS One, 14(11), e0224425. https://doi.org/10.1371/journal.pone.0224425

Yamamoto, M., Nasugawa, T., Kamijo, K., \& Kitamura, H. (2016). A proposal for manual and semi-automatic translation methods of LIWC2001. Proceedings of the 22nd Annual Meeting of the Association for Natural Language Processing, 1185-1188. 
Figure 1

Procedure for the Development of J-LIWC2015 Dictionary.
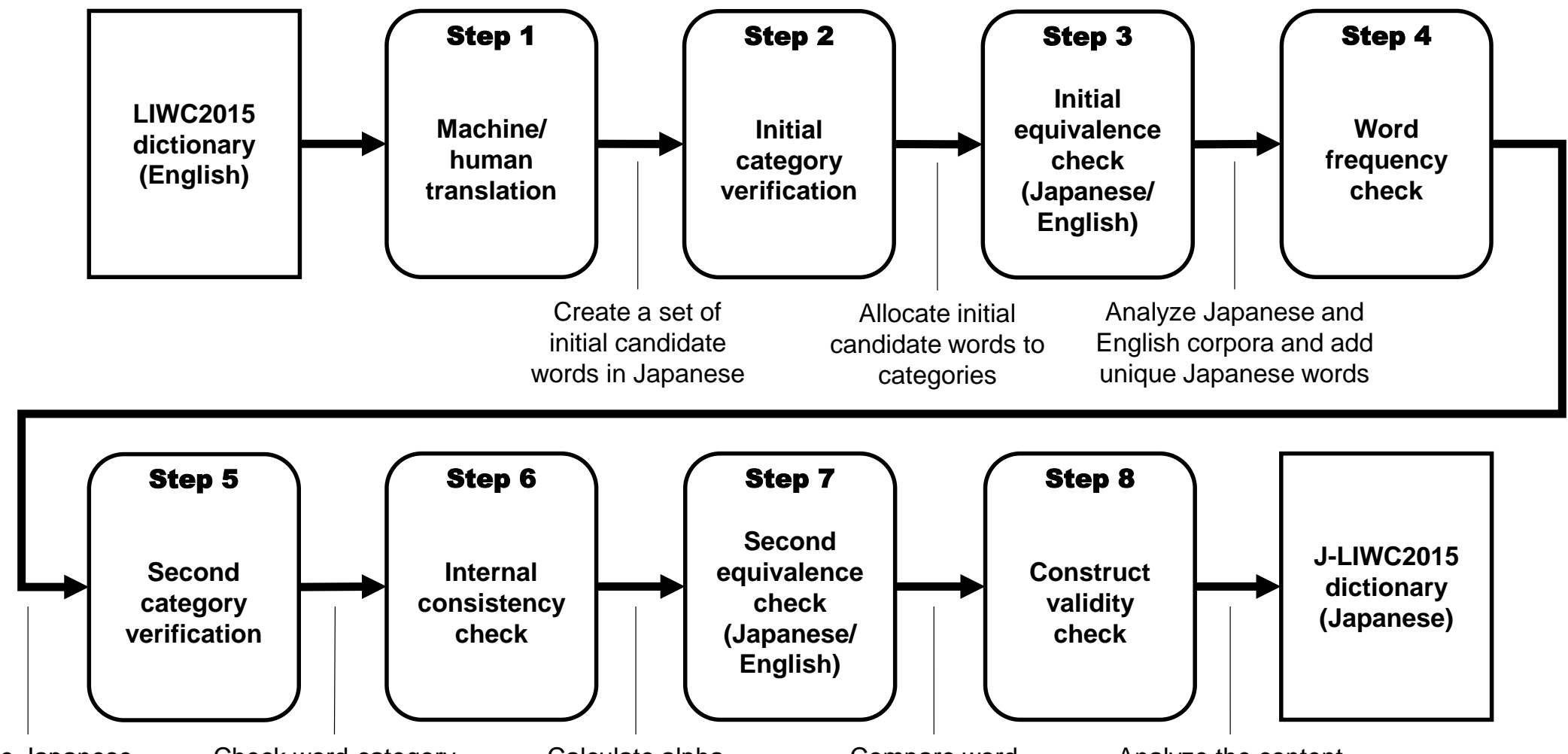

Analyze Japanese corpora (800 million words) and add frequent

Japanese words
Check word-category correspondence by psychologists
Calculate alpha coefficients in each category and finalize dictionary words
Compare word

frequency between Japanese and English corpora
Analyze the content of writing after mood manipulation 


\section{Figure 2}

Word Count and Relative Word Count (\% of Total Words) of Linguistic Categories across Conditions in Emotion Manipulation Task.

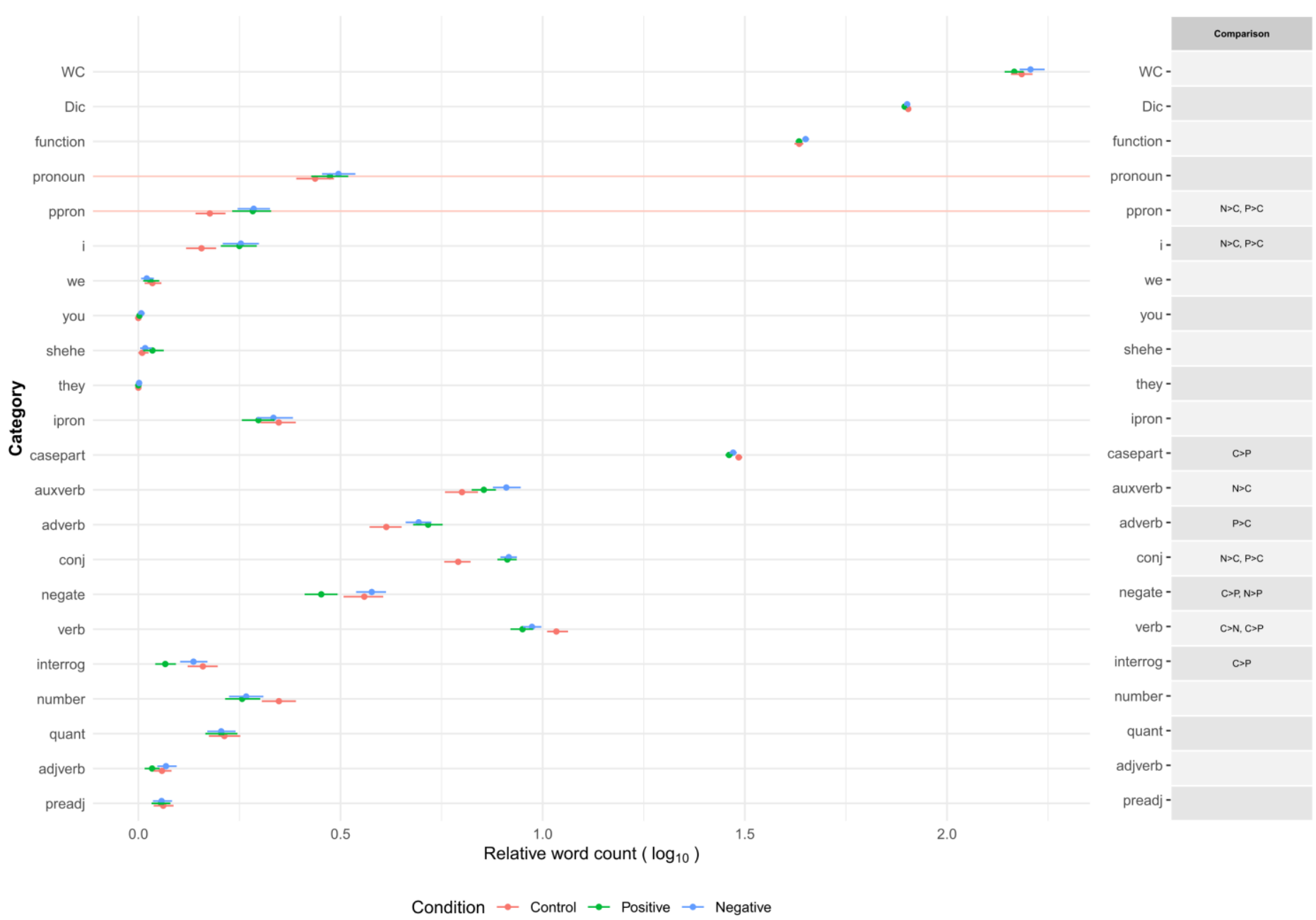


Note. Relative word count is the proportion of dictionary words used to the total number of words in each text. WC $=($ total) word count. Dic $=\%$ of dictionary words. Category names are shown as abbreviations reported in Table 1 . Error bars represent $99.5 \%$ confidence intervals. Multiple comparison results are adjusted by Holm's method (across WC, Dic, and all categories of J-LIWC2015 in Figures 2 and 3) and shown here when adjusted $p s<.005$. 


\section{Figure 3}

Relative Word Count (\% of Total Words) of Psychological Categories across Conditions in Emotion Manipulation Task.
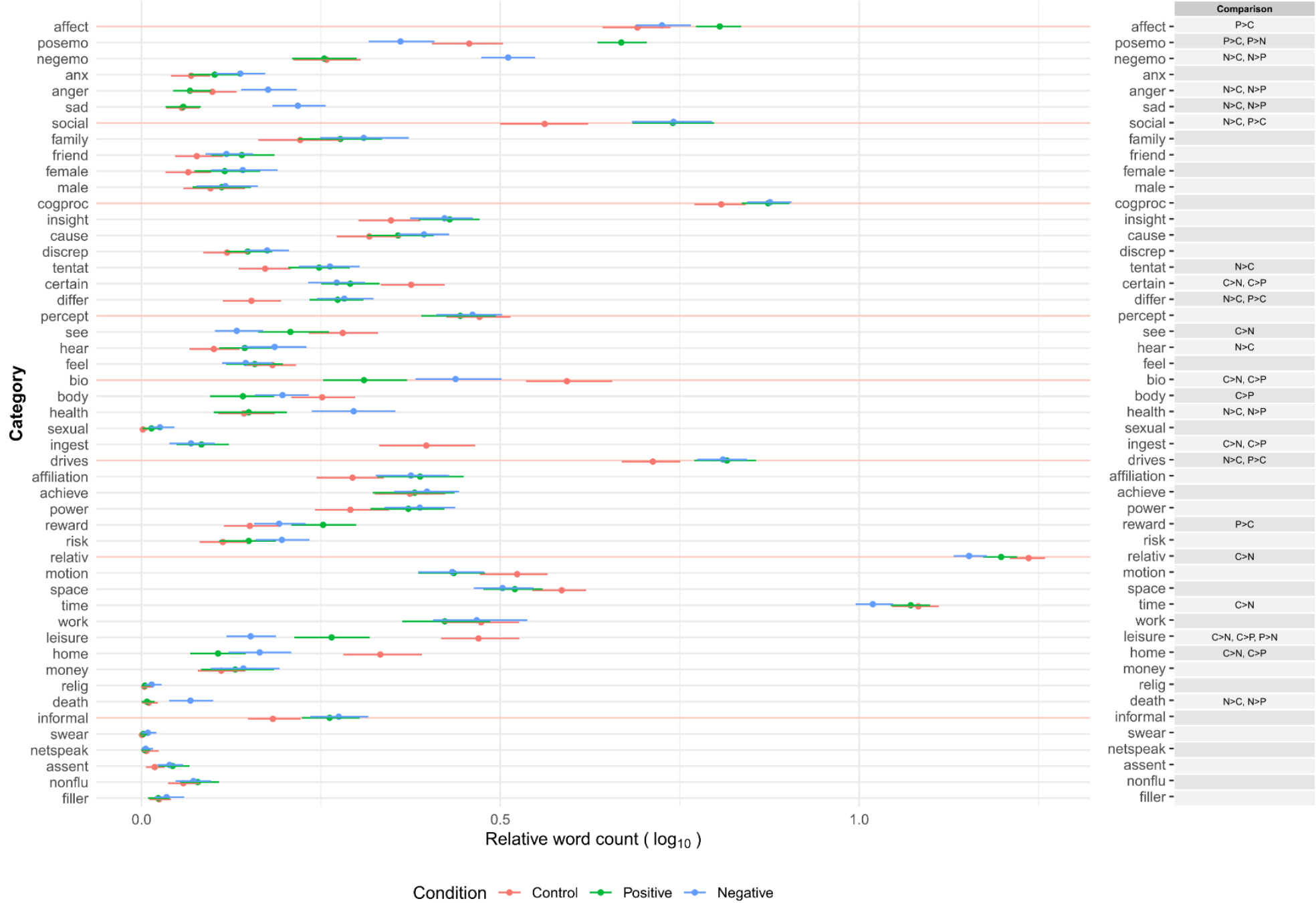
Note. Relative word count is the proportion of dictionary words used to the total number of words in each text. Category names are shown as abbreviations reported in Table 1. Error bars represent 99.5\% confidence intervals. Multiple comparison results are adjusted by Holm's method (across word count, \% of dictionary words, and all categories of J-LIWC2015 in Figures 2 and 3 ) and shown here when $p<.005$. 
Figure 4

A general framework for quantitative language processing in Japanese by J-LIWC2015 dictionary.

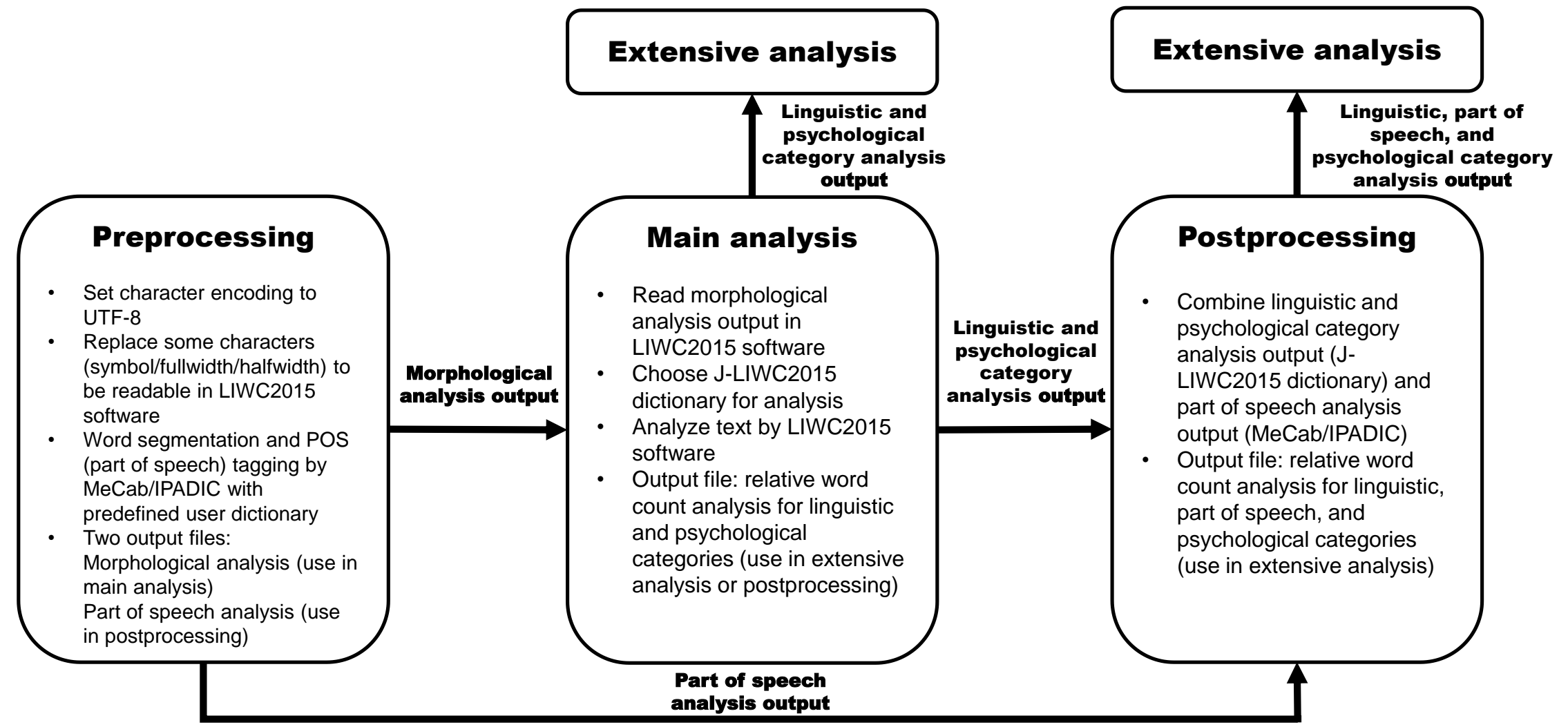

Note. Sample scripts for preprocessing and postprocessing can be downloaded from https://github.com/tasukuigarashi/j-liwc2015. 
Table 1. Categories in J-LIWC2015.

\begin{tabular}{|c|c|c|c|c|}
\hline Category & $\begin{array}{c}\text { Category } \\
\text { (in Japanese) }\end{array}$ & $\begin{array}{l}\text { Output } \\
\text { label }\end{array}$ & Example & $\begin{array}{c}\text { N. of } \\
\text { Words in } \\
\text { category }\end{array}$ \\
\hline Linguistic dimensions & 言語次元 & & & \\
\hline Function words & 機能語 & function & あいつ、非常に、ない & 1808 \\
\hline Pronouns & 代名詞 & pronoun & 私、あなた、ここ & 111 \\
\hline Personal pronouns & 人称代名詞 & ppron & 私、あなた、彼女 & 61 \\
\hline 1st person singular & 一人称単数 & $\mathrm{i}$ & 私、僕、おれ & 13 \\
\hline 1st person plural & 一人称複数 & we & 我々、達、たち & 3 \\
\hline 2nd person & 二人称 & you & あなた、君、お前 & 16 \\
\hline 3rd person singular & 三人称単数 & shehe & 彼女、彼、あいつ & 8 \\
\hline 3rd person plural & 三人称複数 & they & 彼女ら、彼ら、奴等 & 8 \\
\hline Impersonal pronouns & 不定代名詞 & ipron & ここ、之、全て & 75 \\
\hline Case particles ${ }^{\star}$ & 格助詞* & casepart & とか、から、以来 & 187 \\
\hline Auxiliary verbs & 助動詞 & auxverb & だ、できる、如し & 110 \\
\hline Adverbs & 副詞 & adverb & すっかり、非常に、目下 & 1268 \\
\hline Conjunctions & 接続詞 & conj & すなわち、一方、及び & 149 \\
\hline Negations & 否定詞 & negate & ず、ない、未 & 44 \\
\hline Other grammar & その他の文法 & & & \\
\hline Verbs & 動詞 & verb & わかる、行く、住む & 2271 \\
\hline Interrogatives & 疑問詞 & interrog & なぜ、どうして、何 & 18 \\
\hline Numbers & 数詞 & number & ゼロ、百、率 & 52 \\
\hline Quantifiers & 数量詞·助数詞 & quant & 数多く、いろんな、バレル & 261 \\
\hline Adjective verbs ${ }^{*}$ & 形容動詞 & adjverb & シンプル、大まか、平気 & 184 \\
\hline Prenoun adjectival $^{*}$ & 連体詞 & preadj & ほんの、そんな、如何なる & 35 \\
\hline Psychological processes & 心理的プロセス & & & \\
\hline Affective processes & 感情プロセス & affect & おかしい、敏感、マジ & 2067 \\
\hline Positive emotions & ポジティブ感情 & posemo & 上品、善、最愛 & 941 \\
\hline Negative emotions & ネガティブ感情 & negemo & 不信、いいかげん、いや & 1075 \\
\hline Anxiety & 不安 & anx & 不吉、ナーバス、警鐘 & 157 \\
\hline Anger & 怒り & anger & 不快、逆ギレ、ハラスメント & 329 \\
\hline Sadness & 悲しみ & sad & 不幸、悲観、自滅 & 168 \\
\hline Social processes & $\begin{array}{l}\text { 社会的(相互作用) } \\
\text { プロセス }\end{array}$ & social & 迎える、語る、ふれあい & 1027 \\
\hline Family & 家族 & family & 両親、いとこ、一家 & 122 \\
\hline Friends & 友人 & friend & 友達、盟友、相棒 & 92 \\
\hline
\end{tabular}




\begin{tabular}{|c|c|c|c|c|}
\hline Female references & 女性 & female & ウーマン、乙女、ママ & 137 \\
\hline Male references & 男性 & male & おじさん、殿、婿 & 105 \\
\hline Cognitive Processes & 認知プロセス & cogproc & 心がけ、図る、補う & 1307 \\
\hline Insight & 洞察 & insight & 信念、注目、探索 & 384 \\
\hline Causation & 原因 & cause & 誘引、影響、動機 & 229 \\
\hline Discrepancies & 不一致 & discrep & 意外、ふつう、誤 & 107 \\
\hline Tentative & あいまいさ & tentat & 推定、気まぐれ、様々 & 281 \\
\hline Certainty & 確かさ & certain & 常に、厳密、パーフェクト & 247 \\
\hline Differentiation & 差別化 & differ & 識別、相違、対照的 & 137 \\
\hline Perceptual processes & 知覚プロセス & percept & 五感、体験、味 & 970 \\
\hline See & 視覚·知覚 & see & 一見、写す、白 & 351 \\
\hline Hear & 聴覚 & hear & 歌唱、鳴る、静 & 205 \\
\hline Feel & $\begin{array}{l}\text { 感覚(触覚·味覚·嗅 } \\
\text { 覚) }\end{array}$ & feel & 鋭利、感覚、うずうず & 307 \\
\hline Biological processes & 生物学的プロセス & bio & 遺伝、生態、成熟 & 956 \\
\hline Body & 身体 & body & つま先、脳、眠い & 286 \\
\hline Health & 健康 & health & 鎮痛、かゆい、しこり & 384 \\
\hline Sexual & 性 & sexual & ポルノ、欲情、変質者 & 118 \\
\hline Ingestion & 摂取 & ingest & ビール、雑穀、ベジタリアン & 225 \\
\hline Drives & 動因 & drives & 主権、威力、同胞 & 2083 \\
\hline Affiliation & つながり & affiliation & 身内、談笑、友情 & 418 \\
\hline Achievement & 達成 & achieve & 称賛、リーダー、誇る & 546 \\
\hline Power & 社会的地位·権力 & power & ランキング、当局、捕まる & 959 \\
\hline Reward & 報酬 & reward & 発展、向上心、功績 & 237 \\
\hline Risk & リスク & risk & 事故、コスト、セキュリティ & 252 \\
\hline Relativity & 相対性 & relativ & 原点、前後、無限 & 2342 \\
\hline Motion & 動作 & motion & 回す、握る、忍び足 & 844 \\
\hline Space & 空間 & space & 領域、距離、溝 & 760 \\
\hline Time & 時間 & time & やっと、週末、最近 & 814 \\
\hline Personal concerns & 個人的な事柄 & & & \\
\hline Work & 仕事·学業 & work & 転職、取り引き、幼稚園 & 837 \\
\hline Leisure & 趣味·余暇 & leisure & 歌う、園芸、小説 & 399 \\
\hline Home & 家 & home & キッチン、枕、リフォーム & 148 \\
\hline Money & 金銭 & money & 給料、負債、ディスカウント & 317 \\
\hline Religion & 宗教 & relig & 密教、神主、供える & 183 \\
\hline Death & 死 & death & 追悼、不滅、四十九日 & 89 \\
\hline
\end{tabular}




\begin{tabular}{|c|c|c|c|c|}
\hline Informal language & インフォーマル & informal & 何だ、あいつ、み & 589 \\
\hline Swear words & 罵倒 & swear & 非国民、アホ、雑魚 & 56 \\
\hline Netspeak & ネットスラング & netspeak & うр、なう、ぴえん & 346 \\
\hline Assent & うなずき & assent & そう、是非とも、おk & 16 \\
\hline Nonfluencies & 間投詞 & nonflu & ああ、はて、へえ & 121 \\
\hline Filler words & フィラー & filler & うむ、さて、はは & 25 \\
\hline
\end{tabular}

Note. Indents in the category row indicate hierarchical relationships among the categories.

Output labels are used in LIWC2015 software. *Categories included only in J-LIWC2015 (not in LIWC2015). 


\section{Supplementary Materials}

\section{Development of the Japanese Version of the Linguistic Inquiry and Word Count Dictionary 2015 (J-LIWC2015)}

\section{Tasuku Igarashi, Shimpei Okuda, and Kazutoshi Sasahara}

\section{Dictionaries used in Step 1 (Initial Translation)}

For human translation, we referred to Longman Dictionary of Contemporary English (5th edition) (Pearson Education), Collins Cobuild English Dictionary for Advanced Learners ( $3^{\text {rd }}$ edition) (HarperCollins), Kenkyusha's New English-Japanese Dictionary (6 $6^{\text {th }}$ edition) (Kenkyusha), Kenkyusha's New Japanese-English Dictionary (5 $5^{\text {th }}$ edition) (Kenkyusha), Dictionary of English Collocations, the Kenkyusha (Kenkyusha), Kenkyusha's EnglishJapanese Dictionary for the General Reader ( $2^{\text {nd }}$ edition) (Kenkyusha), Kenkyusha's New College English-Japanese Dictionary ( $7^{\text {th }}$ edition) (Kenkyusha), Kenkyusha's New College Japanese-English Dictionary (5 $5^{\text {th }}$ edition) (Kenkyusha), New Shogakukan Random House English-Japanese Dictionary (Shogakukan), Genius English-Japanese Dictionary (Taishukan Shoten), Genius Japanese-English Dictionary ( $2^{\text {nd }}$ edition) (Taishukan Shoten), Saito's Japanese-English dictionary (Nichigai Associates), Unno's Real English Dictionary V5 (Project Pothos), Kōjien (6 $6^{\text {th }}$ edition) (Iwanami Shoten), Thesaurus ( $2^{\text {nd }}$ edition) (Taishukan Shoten), Lifescience (LSD Project), Eijiro (Electronic Dictionary Project), Kanjigen ( $5^{\text {th }}$ revised edition) (Gakken Plus), Urban Dictionary (https://www.urbandictionary.com/), and other internet resources.

\section{Results of Analysis of Variance in Step 8 (Construct Validity Check) Manipulation Check.}

We examined whether the emotion manipulation worked properly. No substantial baseline difference in personality factors was found across the samples in the control, positive emotion, and negative emotion conditions. Multivariate analysis of variance (MANOVA) revealed that the variables varied across the control, positive emotion, and negative emotion conditions, Wilks' $\Lambda=0.201, F(18,978)=65.2, p<.001$, partial $\eta^{2}=.545$. Mean values of each variable in each condition and the results of analysis of variance (ANOVA) are reported in Table S4. As expected, participants in the positive emotion condition rated their experience reported in the essay as more pleasant and positive than those in the control and negative emotion conditions. Participants in the negative emotion condition rated their experience as less pleasant and more negative than those in the control and positive 
emotion conditions. Participants in the control condition rated their experience as less impactful than those in the positive and negative emotion conditions. The positive affect score in the Positive and Negative Affect Schedule (PANAS) was the highest in the positive emotion condition, and the negative affect score in PANAS was the highest in the negative emotion condition. No substantial difference in personality factors was also observed across the conditions. One-sample $t$-tests on the impact score were also conducted to compare the mean values in each condition to the midpoint (7) of the scale (ranging from 2 to 12). The impact scores in the positive and negative emotion conditions were higher than the median, $t(163)=27.0, p<.001, d=2.09$, and $t(178)=14.0, p<.001, d=1.05$, whereas the score in the control condition was not, $t(156)=0.16, p=.872, d=0.01$. The findings indicate that the emotion manipulation was successful.

\section{Multiple Comparison Tests.}

Figure 1 in the manuscript presents the descriptive information of the proportion of word occurrence (and word counts) in linguistic categories (function words and other grammars) in each condition. Figure 2 in the manuscript presents the average proportions of word occurrence in non-linguistic categories in each condition, each followed by multiple comparison tests across the conditions. All following results indicate differences between the conditions at the significant level of adjusted $p<.005$ (Holm's method).

Function words and other grammars.

First-person singular words (e.g., “私” (“l”)) and conjunctions (e.g., “また” (“or”)) appeared more in the positive and negative emotion conditions than in the control condition. Negates (e.g., “ない” (“none”)) were less frequently used in the positive emotion condition than in the negative emotion and control conditions. Verbs (e.g., “する” (“do”)) were more frequently used in the control condition than in the positive and negative emotion conditions. Affect.

Positive emotion words (e.g., “元気” ("fine”)) were more frequently used in the positive emotion category than in the other categories. In contrast, negative emotion words (e.g., “駄目” (“ruin”)), including words in the anger (e.g., “激怒” (“furious”)) and sad (e.g., “嘆 <" ("lament")) categories, were more frequently used in the negative emotion category than in the other categories.

Social.

Words in the social category (e.g., “話す” (“talk”)) were more frequently used in the positive and negative emotion condition than in the control condition.

\section{Cognitive processes.}

In the control condition, words in the certainty category (e.g., “必ず” (“sure”)) were more frequently used, and words in the difference category (e.g., “しかし” (“however”)) were 
less frequently used than in the other conditions.

Biological processes.

The use of words in the biological process category was more frequent in the control condition than in the other conditions. Of those, health-related words (e.g., “腰痛” ("backache")) were more frequently used in the negative emotion condition than in the other conditions. Ingestion-related words (e.g., “技菓子” (“sweets”)) were more frequently used in the control condition than in the other conditions.

Drives.

Words in the drive category (e.g., “影響” (“effect”)) were more frequently used in the positive and negative emotion conditions than in the control condition.

Personal concerns.

Leisure-related words (e.g., “遊ぶ” ("play")) were frequently used the most in the control condition, followed by in the positive emotion condition and the negative emotion condition. Home-related words (e.g., "家” ("house")) were more frequently used in the control condition than in the other conditions. Death-related words (e.g., "死" ("die")) were more frequently used in the negative emotion condition than in the other conditions.

Perceptual process, relativity, and informal.

No category showed substantial differences in word use across two or more conditions.

\section{Sample scripts for preprocessing and postprocessing}

The latest version of the preprocessing/postprocessing scripts (and related information) is available at https://github.com/tasukuigarashi/j-liwc2015. Figure 4 in the main article explains the contents of preprocessing and postprocessing. 
Table S1. Relative word count (\% of total words) of each category in ten corpora.

\begin{tabular}{|c|c|c|c|c|c|c|c|c|c|c|c|}
\hline Category/Corpus & $\begin{array}{l}\text { Aozora } \\
\text { Bunko } \\
\text { (novels) }\end{array}$ & $\begin{array}{l}\text { Aozora } \\
\text { Bunko } \\
\text { (essays) }\end{array}$ & $\begin{array}{l}\text { National } \\
\text { Diet } \\
\text { Minutes } \\
\text { (plenary } \\
\text { sessions) }\end{array}$ & $\begin{array}{c}\text { National } \\
\text { Diet } \\
\text { Minutes } \\
\text { (budget } \\
\text { committee) }\end{array}$ & $\begin{array}{c}\text { Livedoor } \\
\text { News }\end{array}$ & NUCC & Nicovideo & $\begin{array}{c}\text { Open } \\
\text { 2channel }\end{array}$ & $\begin{array}{l}\text { TED } \\
\text { Talks }\end{array}$ & Twitter & $\begin{array}{l}\text { Grand } \\
\text { mean } \\
(\mathrm{SD})\end{array}$ \\
\hline Unit of analysis (text) & Work & Work & Session & Session & $\begin{array}{l}\text { News } \\
\text { article }\end{array}$ & $\begin{array}{c}\text { Dyadic } \\
\text { conversati } \\
\text { on }\end{array}$ & $\begin{array}{c}\text { Comments } \\
\text { on video }\end{array}$ & $\begin{array}{c}\text { Conversat } \\
\text { ion with } \\
\text { replies }\end{array}$ & Talk & Account & \\
\hline N. of texts & 3114 & 3722 & 6697 & 3786 & 7346 & 129 & 19041 & 181666 & 5156 & 2748 & \\
\hline N. of words & 42275370 & 11947794 & 74454270 & 149087438 & 4275203 & 1097307 & 502295443 & 24830799 & 10592456 & 568784 & \\
\hline Average word count per text & 13575.91 & 3210.05 & 11117.56 & 39378.62 & 581.98 & 8506.26 & 26379.68 & 136.68 & 2054.39 & 206.98 & \\
\hline Dictionary words (\%) & 69.23 & 62.68 & 70.32 & 72.39 & 63.63 & 73.27 & 53.03 & 65.55 & 74.16 & 53.73 & $\begin{array}{l}65.80 \\
(7.64)\end{array}$ \\
\hline \multicolumn{12}{|l|}{ Linguistic dimensions } \\
\hline Function words & 41.85 & 36.73 & 37.89 & 42.71 & 33.65 & 38.96 & 25.45 & 38.46 & 43.98 & 27.69 & $\begin{array}{l}36.74 \\
(5.85)\end{array}$ \\
\hline Pronouns & 3.46 & 2.93 & 2.26 & 3.34 & 1.24 & 4.66 & 2.85 & 2.24 & 3.63 & 1.81 & $\begin{array}{l}2.84 \\
(0.94)\end{array}$ \\
\hline Personal pronouns & 1.40 & 1.03 & 0.78 & 0.87 & 0.39 & 1.09 & 0.68 & 0.88 & 1.30 & 0.79 & $\begin{array}{c}0.92 \\
(0.28)\end{array}$ \\
\hline 1st person singular & 0.62 & 0.58 & 0.19 & 0.49 & 0.20 & 0.52 & 0.11 & 0.21 & 0.88 & 0.42 & $\begin{array}{c}0.42 \\
(0.23)\end{array}$ \\
\hline 1st person plural & 0.09 & 0.12 & 0.03 & 0.06 & 0.09 & 0.06 & 0.02 & 0.03 & 0.46 & 0.06 & $\begin{array}{c}0.10 \\
(0.12)\end{array}$ \\
\hline 2nd person & 0.22 & 0.13 & 0.48 & 0.22 & 0.05 & 0.10 & 0.13 & 0.18 & 0.11 & 0.13 & $\begin{array}{c}0.18 \\
(0.11)\end{array}$ \\
\hline
\end{tabular}




\begin{tabular}{|c|c|c|c|c|c|c|c|c|c|c|c|}
\hline 3rd person singular & 0.31 & 0.10 & 0.00 & 0.00 & 0.09 & 0.04 & 0.13 & 0.17 & 0.18 & 0.05 & $\begin{array}{c}0.11 \\
(0.09)\end{array}$ \\
\hline 3rd person plural & 0.04 & 0.04 & 0.02 & 0.06 & 0.01 & 0.00 & 0.01 & 0.02 & 0.10 & 0.01 & $\begin{array}{c}0.03 \\
(0.03)\end{array}$ \\
\hline Impersonal pronouns & 2.16 & 1.99 & 1.50 & 2.40 & 0.90 & 3.58 & 2.19 & 1.42 & 2.47 & 1.07 & $\begin{array}{c}1.97 \\
(0.75)\end{array}$ \\
\hline Case particles & 27.98 & 25.30 & 27.45 & 28.30 & 24.83 & 18.19 & 12.66 & 22.65 & 29.40 & 17.08 & $\begin{array}{l}23.38 \\
(5.35)\end{array}$ \\
\hline Auxiliary verbs & 5.82 & 4.92 & 4.50 & 5.88 & 4.29 & 8.00 & 5.57 & 7.57 & 6.14 & 4.87 & $\begin{array}{c}5.76 \\
(1.17)\end{array}$ \\
\hline Adverbs & 3.63 & 2.69 & 2.70 & 4.00 & 2.33 & 5.50 & 2.31 & 3.39 & 3.12 & 2.53 & $\begin{array}{c}3.22 \\
(0.93)\end{array}$ \\
\hline Conjunctions & 5.72 & 4.98 & 5.05 & 6.94 & 5.61 & 6.79 & 3.72 & 6.90 & 6.25 & 4.36 & $\begin{array}{c}5.63 \\
(1.05)\end{array}$ \\
\hline Negations & 2.42 & 2.06 & 1.45 & 2.16 & 1.69 & 3.74 & 3.19 & 3.96 & 2.05 & 2.23 & $\begin{array}{c}2.49 \\
(0.81)\end{array}$ \\
\hline Other grammar & & & & & & & & & & & \\
\hline Verbs & 6.23 & 4.76 & 4.72 & 4.61 & 5.37 & 5.62 & 3.98 & 6.53 & 6.39 & 5.39 & $\begin{array}{c}5.36 \\
(0.81)\end{array}$ \\
\hline Interrogatives & 0.48 & 0.29 & 0.10 & 0.28 & 0.23 & 1.09 & 0.42 & 0.49 & 0.59 & 0.31 & $\begin{array}{c}0.43 \\
(0.26)\end{array}$ \\
\hline Numbers & 1.88 & 2.89 & 3.36 & 3.71 & 1.95 & 1.72 & 1.15 & 1.08 & 1.42 & 1.44 & $\begin{array}{c}2.06 \\
(0.89)\end{array}$ \\
\hline Quantifiers & 0.48 & 0.62 & 0.82 & 0.99 & 0.94 & 0.78 & 0.61 & 0.76 & 1.02 & 0.74 & $\begin{array}{c}0.78 \\
(0.17)\end{array}$ \\
\hline Adjective verbs & 0.13 & 0.17 & 0.35 & 0.27 & 0.32 & 0.09 & 0.17 & 0.27 & 0.31 & 0.19 & $\begin{array}{c}0.23 \\
(0.08)\end{array}$ \\
\hline Prenoun adjectival & 0.27 & 0.27 & 0.21 & 0.76 & 0.18 & 0.59 & 0.11 & 0.34 & 0.25 & 0.16 & $\begin{array}{c}0.31 \\
(0.19)\end{array}$ \\
\hline
\end{tabular}


Psychological processes

\begin{tabular}{|c|c|c|c|c|c|c|c|c|c|c|c|}
\hline Affect & 2.67 & 2.41 & 3.14 & 2.52 & 3.60 & 3.49 & 4.89 & 4.38 & 3.62 & 4.21 & $\begin{array}{c}3.49 \\
(0.79)\end{array}$ \\
\hline Positive emotions & 1.28 & 1.33 & 1.88 & 1.30 & 2.37 & 1.90 & 2.93 & 2.11 & 2.25 & 2.71 & $\begin{array}{c}2.01 \\
(0.55)\end{array}$ \\
\hline Negative emotions & 1.27 & 0.94 & 1.18 & 1.09 & 1.04 & 1.30 & 1.71 & 1.96 & 1.21 & 1.28 & $\begin{array}{r}1.30 \\
(0.29)\end{array}$ \\
\hline Anxiety & 0.21 & 0.13 & 0.23 & 0.17 & 0.19 & 0.11 & 0.12 & 0.21 & 0.23 & 0.16 & $\begin{array}{c}0.18 \\
(0.04)\end{array}$ \\
\hline Anger & 0.46 & 0.32 & 0.26 & 0.21 & 0.33 & 0.45 & 0.67 & 0.78 & 0.33 & 0.45 & $\begin{array}{c}0.43 \\
(0.17)\end{array}$ \\
\hline Sadness & 0.26 & 0.22 & 0.11 & 0.08 & 0.14 & 0.15 & 0.33 & 0.26 & 0.17 & 0.22 & $\begin{array}{c}0.19 \\
(0.07)\end{array}$ \\
\hline Social processes & 4.14 & 3.24 & 4.50 & 3.54 & 4.49 & 3.62 & 2.72 & 4.03 & 4.11 & 4.42 & $\begin{array}{c}3.88 \\
(0.56)\end{array}$ \\
\hline Family & 0.63 & 0.40 & 0.04 & 0.04 & 0.36 & 0.41 & 0.26 & 0.28 & 0.33 & 0.30 & $\begin{array}{c}0.31 \\
(0.16)\end{array}$ \\
\hline Friends & 0.34 & 0.21 & 0.52 & 0.22 & 0.33 & 0.28 & 0.25 & 0.39 & 0.24 & 0.49 & $\begin{array}{c}0.33 \\
(0.10)\end{array}$ \\
\hline Female references & 0.61 & 0.33 & 0.02 & 0.02 & 0.44 & 0.21 & 0.22 & 0.24 & 0.24 & 0.22 & $\begin{array}{c}0.25 \\
(0.17)\end{array}$ \\
\hline Male references & 0.73 & 0.35 & 0.02 & 0.01 & 0.29 & 0.23 & 0.40 & 0.32 & 0.30 & 0.33 & $\begin{array}{c}0.30 \\
(0.19)\end{array}$ \\
\hline Cognitive Processes & 4.15 & 4.63 & 6.96 & 8.13 & 5.38 & 6.73 & 3.49 & 7.42 & 7.50 & 5.06 & $\begin{array}{c}5.95 \\
(1.52)\end{array}$ \\
\hline Insight & 1.04 & 1.07 & 2.31 & 2.64 & 1.68 & 1.64 & 0.80 & 2.08 & 2.24 & 1.39 & $\begin{array}{c}1.69 \\
(0.59)\end{array}$ \\
\hline Causation & 0.86 & 1.36 & 1.58 & 1.70 & 1.38 & 0.98 & 0.58 & 1.19 & 1.96 & 0.93 & $\begin{array}{c}1.25 \\
(0.40)\end{array}$ \\
\hline
\end{tabular}




\begin{tabular}{|c|c|c|c|c|c|c|c|c|c|c|c|}
\hline Discrepancies & 0.29 & 0.27 & 0.86 & 1.06 & 0.41 & 0.39 & 0.48 & 0.67 & 0.42 & 0.53 & $\begin{array}{c}0.54 \\
(0.24)\end{array}$ \\
\hline Tentative & 0.90 & 0.74 & 0.88 & 1.21 & 0.79 & 1.14 & 0.50 & 1.35 & 1.29 & 0.86 & $\begin{array}{c}0.96 \\
(0.26)\end{array}$ \\
\hline Certainty & 0.58 & 0.75 & 1.19 & 1.17 & 0.72 & 0.88 & 0.56 & 0.86 & 1.25 & 0.72 & $\begin{array}{c}0.87 \\
(0.24)\end{array}$ \\
\hline Differentiation & 0.76 & 0.69 & 0.71 & 1.20 & 0.79 & 2.05 & 0.77 & 2.06 & 1.12 & 1.08 & $\begin{array}{c}1.12 \\
(0.50)\end{array}$ \\
\hline Perceptual processes & 2.46 & 1.90 & 0.58 & 0.75 & 2.43 & 1.73 & 2.06 & 1.69 & 2.23 & 1.81 & $\begin{array}{c}1.76 \\
(0.61)\end{array}$ \\
\hline See & 1.25 & 0.99 & 0.19 & 0.23 & 1.34 & 0.56 & 0.79 & 0.62 & 1.02 & 0.78 & $\begin{array}{c}0.78 \\
(0.37)\end{array}$ \\
\hline Hear & 0.64 & 0.44 & 0.26 & 0.40 & 0.55 & 0.67 & 0.81 & 0.53 & 0.68 & 0.50 & $\begin{array}{c}0.55 \\
(0.15)\end{array}$ \\
\hline Feel & 0.47 & 0.34 & 0.08 & 0.09 & 0.35 & 0.33 & 0.28 & 0.38 & 0.35 & 0.36 & $\begin{array}{c}0.30 \\
(0.12)\end{array}$ \\
\hline Biological processes & 1.80 & 1.24 & 0.43 & 0.32 & 1.18 & 1.13 & 1.11 & 1.26 & 1.79 & 1.47 & $\begin{array}{c}1.17 \\
(0.46)\end{array}$ \\
\hline Body & 1.22 & 0.63 & 0.08 & 0.07 & 0.44 & 0.37 & 0.60 & 0.49 & 0.72 & 0.57 & $\begin{array}{c}0.52 \\
(0.31)\end{array}$ \\
\hline Health & 0.29 & 0.34 & 0.26 & 0.16 & 0.31 & 0.22 & 0.19 & 0.36 & 0.76 & 0.37 & $\begin{array}{c}0.33 \\
(0.16)\end{array}$ \\
\hline Sexual & 0.02 & 0.03 & 0.00 & 0.00 & 0.06 & 0.01 & 0.17 & 0.14 & 0.06 & 0.13 & $\begin{array}{c}0.06 \\
(0.06)\end{array}$ \\
\hline Ingestion & 0.30 & 0.25 & 0.10 & 0.09 & 0.34 & 0.56 & 0.19 & 0.33 & 0.29 & 0.39 & $\begin{array}{c}0.28 \\
(0.13)\end{array}$ \\
\hline Drives & 3.33 & 3.62 & 8.83 & 6.37 & 5.22 & 2.81 & 3.41 & 4.81 & 5.69 & 4.60 & $\begin{array}{c}4.87 \\
(1.71)\end{array}$ \\
\hline
\end{tabular}




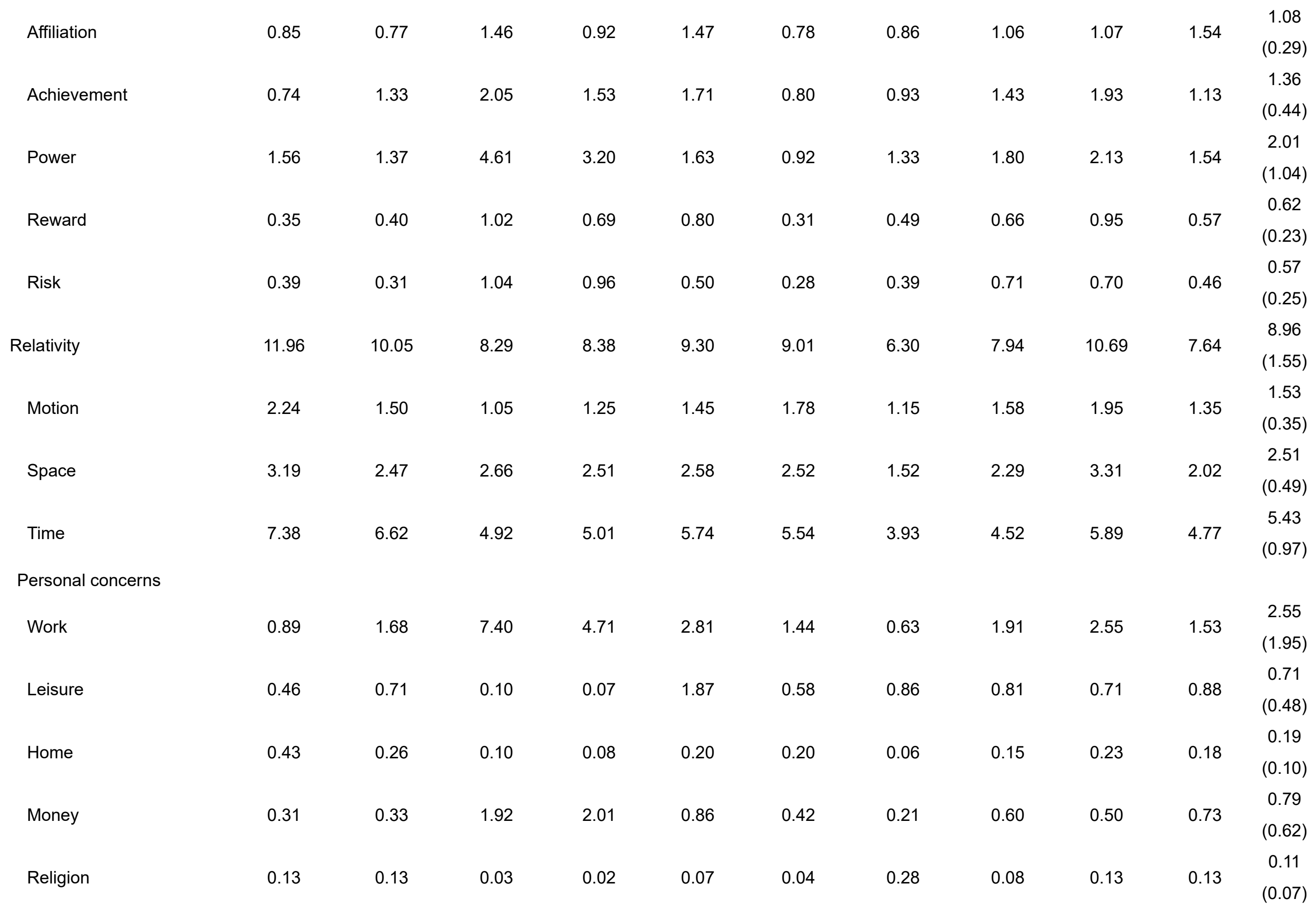




\begin{tabular}{|c|c|c|c|c|c|c|c|c|c|c|c|}
\hline Death & 0.21 & 0.15 & 0.07 & 0.03 & 0.06 & 0.04 & 0.24 & 0.16 & 0.13 & 0.09 & $\begin{array}{c}0.12 \\
(0.07)\end{array}$ \\
\hline Informal language & 1.77 & 0.98 & 0.27 & 0.87 & 0.93 & 13.40 & 9.09 & 3.01 & 0.88 & 2.36 & $\begin{array}{c}3.36 \\
(4.13)\end{array}$ \\
\hline Swear words & 0.05 & 0.02 & 0.00 & 0.00 & 0.02 & 0.03 & 0.25 & 0.22 & 0.01 & 0.08 & $\begin{array}{c}0.07 \\
(0.09)\end{array}$ \\
\hline Netspeak & 0.02 & 0.02 & 0.01 & 0.02 & 0.07 & 0.97 & 1.10 & 0.32 & 0.14 & 0.33 & $\begin{array}{c}0.30 \\
(0.39)\end{array}$ \\
\hline Assent & 0.22 & 0.10 & 0.02 & 0.10 & 0.10 & 4.54 & 0.45 & 0.42 & 0.13 & 0.19 & $\begin{array}{c}0.63 \\
(1.31)\end{array}$ \\
\hline Nonfluencies & 0.77 & 0.44 & 0.10 & 0.25 & 0.19 & 3.95 & 6.34 & 1.01 & 0.17 & 0.67 & $\begin{array}{r}1.39 \\
(1.97)\end{array}$ \\
\hline Filler words & 0.25 & 0.13 & 0.04 & 0.20 & 0.08 & 1.78 & 3.41 & 0.41 & 0.12 & 0.34 & $\begin{array}{c}0.68 \\
(1.03)\end{array}$ \\
\hline
\end{tabular}

Note. Relative word count is the proportion of dictionary word use to the total number of words in each text. Grand mean (SD) is the unweighted mean value (standard deviation) across the ten corpora. 
Table S2. Internal consistency of each category.

\begin{tabular}{|c|c|c|c|c|c|}
\hline Category & Uncorrected $\alpha$ & Corrected $\alpha$ & Category & Uncorrected $\alpha$ & Corrected $\alpha$ \\
\hline Linguistic dimensions & & & Cognitive Processes & 0.478 & 0.901 \\
\hline Function words & 0.511 & 0.913 & Insight & 0.353 & 0.845 \\
\hline Pronouns & 0.195 & 0.708 & Causation & 0.176 & 0.681 \\
\hline Personal pronouns & 0.045 & 0.321 & Discrepancies & 0.257 & 0.775 \\
\hline 1st person singular & 0.042 & 0.305 & Tentative & 0.317 & 0.823 \\
\hline 1st person plural & 0.029 & 0.229 & Certainty & 0.296 & 0.808 \\
\hline 2nd person & 0.044 & 0.316 & Differentiation & 0.359 & 0.849 \\
\hline 3rd person singular & 0.089 & 0.494 & Perceptual processes & 0.510 & 0.912 \\
\hline 3rd person plural & 0.039 & 0.287 & See & 0.477 & 0.901 \\
\hline Impersonal pronouns & 0.204 & 0.720 & Hear & 0.425 & 0.881 \\
\hline Case particles ${ }^{*}$ & 0.369 & 0.854 & Feel & 0.310 & 0.818 \\
\hline Auxiliary verbs & 0.359 & 0.848 & Biological processes & 0.572 & 0.930 \\
\hline Adverbs & 0.434 & 0.885 & Body & 0.459 & 0.894 \\
\hline Conjunctions & 0.242 & 0.762 & Health & 0.555 & 0.926 \\
\hline Negations & 0.223 & 0.742 & Sexual & 0.302 & 0.812 \\
\hline Other grammar & & & Ingestion & 0.490 & 0.906 \\
\hline Verbs & 0.262 & 0.780 & Drives & 0.368 & 0.854 \\
\hline Interrogatives & 0.261 & 0.779 & Affiliation & 0.287 & 0.801 \\
\hline Numbers & 0.582 & 0.933 & Achievement & 0.313 & 0.820 \\
\hline Quantifiers & 0.179 & 0.686 & Power & 0.401 & 0.870 \\
\hline Adjective verbs* & 0.206 & 0.722 & Reward & 0.319 & 0.824 \\
\hline Prenoun adjectival $^{*}$ & 0.215 & 0.732 & Risk & 0.336 & 0.835 \\
\hline Psychological processes & & & Relativity & 0.418 & 0.878 \\
\hline Affect & 0.438 & 0.886 & Motion & 0.358 & 0.848 \\
\hline Positive emotions & 0.355 & 0.847 & Space & 0.437 & 0.886 \\
\hline Negative emotions & 0.428 & 0.882 & Time & 0.299 & 0.810 \\
\hline Anxiety & 0.273 & 0.790 & Personal concerns & & \\
\hline Anger & 0.413 & 0.876 & Work & 0.541 & 0.922 \\
\hline Sadness & 0.300 & 0.811 & Leisure & 0.352 & 0.844 \\
\hline Social processes & 0.449 & 0.891 & Home & 0.398 & 0.869 \\
\hline Family & 0.511 & 0.913 & Money & 0.617 & 0.941 \\
\hline Friends & 0.137 & 0.614 & Religion & 0.292 & 0.805 \\
\hline Female references & 0.385 & 0.862 & Death & 0.350 & 0.843 \\
\hline \multirow[t]{6}{*}{ Male references } & 0.162 & 0.659 & Informal language & 0.396 & 0.868 \\
\hline & & & Swear words & 0.222 & 0.741 \\
\hline & & & Netspeak & 0.049 & 0.341 \\
\hline & & & Assent & 0.102 & 0.531 \\
\hline & & & Nonfluencies & 0.254 & 0.773 \\
\hline & & & Filler words & 0.210 & 0.726 \\
\hline
\end{tabular}


Note. Internal consistency represents the mean values of alpha coefficients calculated at each of the ten corpora in Table S1; Uncorrected $\alpha$ is Cronbach's alpha coefficient averaged over the ten corpora; Corrected $\alpha$ is calculated based on the Spearman-Brown prediction formula; ${ }^{*}$ Categories included only in J-LIWC2015 (not in LIWC2015). 
Table S3. Relative word count (\% of total words) in J-LIWC2015 and LIWC2015.

\begin{tabular}{|c|c|c|c|c|c|c|c|c|c|c|c|c|}
\hline \multirow{4}{*}{ Category } & \multicolumn{4}{|c|}{ TED Talks $(N=4509)$} & \multicolumn{4}{|c|}{ Bible $(N=1372)$} & \multicolumn{4}{|c|}{ TED + Bible $(N=5887)$} \\
\hline & \multicolumn{2}{|c|}{ Mean } & \multicolumn{2}{|c|}{ Equivalence } & \multicolumn{2}{|c|}{ Mean } & \multicolumn{2}{|c|}{ Equivalence } & \multicolumn{2}{|c|}{ Grand mean } & \multicolumn{2}{|c|}{ Equivalence } \\
\hline & J-LIWC & LIWC & \multirow{2}{*}{$g$} & \multirow{2}{*}{$r$} & J-LIWC & LIWC & \multirow{2}{*}{$g$} & \multirow{2}{*}{$r$} & J-LIWC & LIWC & \multirow{2}{*}{$g$} & \multirow{2}{*}{$r$} \\
\hline & 2015 & 2015 & & & 2015 & 2015 & & & 2015 & 2015 & & \\
\hline Word count (mean) & 1988.96 & 1623.76 & 0.34 & 0.979 & 831.26 & 666.39 & 0.42 & 0.460 & 1718.87 & 1400.41 & 0.30 & 0.967 \\
\hline Dictionary words (\%) & 74.19 & 85.10 & -2.43 & 0.592 & 75.49 & 85.98 & -2.30 & 0.377 & 74.50 & 85.31 & -2.39 & 0.540 \\
\hline \multicolumn{13}{|l|}{ Linguistic dimensions } \\
\hline Function words & 43.96 & 53.28 & -2.35 & 0.496 & 49.03 & 58.13 & -2.11 & 0.373 & 45.14 & 54.41 & -2.03 & 0.555 \\
\hline Pronouns & 3.57 & 14.37 & -3.52 & 0.708 & 6.80 & 15.73 & -2.48 & 0.289 & 4.33 & 14.68 & -3.08 & 0.486 \\
\hline Personal pronouns & 1.27 & 7.72 & -2.71 & 0.738 & 4.17 & 11.55 & -2.10 & 0.356 & 1.95 & 8.61 & -2.19 & 0.627 \\
\hline 1st person singular & 0.86 & 2.19 & -0.78 & 0.786 & 0.20 & 2.43 & -1.09 & -0.063 & 0.71 & 2.25 & -0.85 & 0.567 \\
\hline 1st person plural & 0.46 & 1.90 & -1.49 & 0.416 & 0.57 & 0.68 & -0.10 & 0.293 & 0.49 & 1.62 & -1.07 & 0.297 \\
\hline 2nd person & 0.11 & 1.66 & -1.56 & 0.529 & 1.52 & 2.80 & -0.63 & 0.337 & 0.44 & 1.93 & -1.05 & 0.426 \\
\hline 3rd person singular & 0.18 & 0.82 & -0.71 & 0.718 & 0.58 & 3.61 & -1.58 & 0.187 & 0.27 & 1.47 & -0.81 & 0.510 \\
\hline 3rd person plural & 0.09 & 1.14 & -1.92 & 0.460 & 0.65 & 2.04 & -1.08 & 0.244 & 0.22 & 1.35 & -1.34 & 0.403 \\
\hline Impersonal pronouns & 2.43 & 6.64 & -2.84 & 0.564 & 2.97 & 4.17 & -0.77 & 0.018 & 2.56 & 6.06 & -2.09 & 0.206 \\
\hline Auxiliary verbs & 6.14 & 8.28 & -1.32 & 0.355 & 5.74 & 7.60 & -0.79 & 0.360 & 6.05 & 8.12 & -1.13 & 0.360 \\
\hline Adverbs & 3.09 & 5.40 & -1.97 & 0.513 & 2.69 & 2.51 & 0.16 & 0.075 & 3.00 & 4.73 & -1.19 & 0.425 \\
\hline Conjunctions & 6.23 & 7.16 & -0.81 & 0.230 & 5.98 & 8.19 & -1.02 & 0.297 & 6.17 & 7.40 & -0.83 & 0.232 \\
\hline Negations & 2.05 & 1.20 & 1.36 & 0.442 & 1.88 & 1.39 & 0.40 & 0.300 & 2.01 & 1.25 & 0.95 & 0.351 \\
\hline \multicolumn{13}{|l|}{ Other grammar } \\
\hline Verbs & 6.39 & 15.16 & -3.60 & 0.256 & 6.23 & 13.86 & -2.78 & 0.174 & 6.35 & 14.86 & -3.35 & 0.234 \\
\hline Interrogatives & 0.59 & 1.84 & -2.37 & 0.503 & 0.28 & 2.10 & -2.35 & 0.181 & 0.52 & 1.90 & -2.28 & 0.306 \\
\hline Numbers & 1.40 & 2.02 & -0.52 & 0.832 & 1.15 & 1.53 & -0.20 & 0.280 & 1.35 & 1.91 & -0.41 & 0.594 \\
\hline Quantifiers & 1.01 & 2.42 & -2.05 & 0.407 & 0.58 & 1.50 & -1.32 & 0.247 & 0.91 & 2.21 & -1.72 & 0.456 \\
\hline
\end{tabular}




\begin{tabular}{|c|c|c|c|c|c|c|c|c|c|c|c|c|}
\hline Affective processes & 3.64 & 4.18 & -0.35 & 0.803 & 4.05 & 4.23 & -0.07 & 0.590 & 3.73 & 4.19 & -0.25 & 0.705 \\
\hline Positive emotions & 2.24 & 2.73 & -0.45 & 0.734 & 2.51 & 2.28 & 0.12 & 0.534 & 2.30 & 2.62 & -0.24 & 0.607 \\
\hline Negative emotions & 1.23 & 1.40 & -0.18 & 0.835 & 1.53 & 1.94 & -0.31 & 0.347 & 1.30 & 1.52 & -0.21 & 0.658 \\
\hline Anxiety & 0.24 & 0.27 & -0.10 & 0.781 & 0.18 & 0.33 & -0.42 & 0.153 & 0.22 & 0.29 & -0.18 & 0.625 \\
\hline Anger & 0.34 & 0.36 & -0.06 & 0.710 & 0.78 & 0.65 & 0.20 & 0.248 & 0.44 & 0.43 & 0.03 & 0.536 \\
\hline Sadness & 0.18 & 0.27 & -0.33 & 0.706 & 0.29 & 0.37 & -0.13 & 0.093 & 0.20 & 0.29 & -0.23 & 0.371 \\
\hline Social processes & 4.11 & 9.76 & -2.01 & 0.786 & 7.73 & 15.55 & -2.24 & 0.260 & 4.96 & 11.11 & -1.70 & 0.743 \\
\hline Family & 0.34 & 0.28 & 0.11 & 0.853 & 0.81 & 0.97 & -0.14 & 0.503 & 0.45 & 0.44 & 0.01 & 0.659 \\
\hline Friends & 0.24 & 0.16 & 0.30 & 0.406 & 0.18 & 0.12 & 0.18 & 0.077 & 0.23 & 0.15 & 0.27 & 0.309 \\
\hline Female references & 0.25 & 0.52 & -0.33 & 0.879 & 0.34 & 0.72 & -0.32 & 0.246 & 0.27 & 0.57 & -0.32 & 0.646 \\
\hline Male references & 0.30 & 0.76 & -0.53 & 0.697 & 1.14 & 4.89 & -1.67 & 0.277 & 0.49 & 1.72 & -0.67 & 0.587 \\
\hline Cognitive Processes & 7.50 & 11.70 & -1.89 & 0.767 & 4.69 & 6.66 & -0.81 & 0.454 & 6.85 & 10.53 & -1.29 & 0.791 \\
\hline Insight & 2.25 & 2.51 & -0.25 & 0.805 & 0.78 & 1.02 & -0.29 & 0.482 & 1.90 & 2.16 & -0.22 & 0.822 \\
\hline Causation & 1.96 & 2.11 & -0.19 & 0.652 & 1.09 & 1.09 & -0.01 & 0.095 & 1.76 & 1.87 & -0.13 & 0.648 \\
\hline Discrepancies & 0.41 & 1.41 & -1.90 & 0.456 & 0.32 & 0.54 & -0.45 & 0.262 & 0.39 & 1.21 & -1.40 & 0.410 \\
\hline Tentative & 1.28 & 2.56 & -1.56 & 0.582 & 0.92 & 1.02 & -0.11 & 0.307 & 1.20 & 2.20 & -1.04 & 0.510 \\
\hline Certainty & 1.25 & 1.40 & -0.27 & 0.492 & 1.03 & 1.27 & -0.31 & 0.254 & 1.20 & 1.37 & -0.28 & 0.406 \\
\hline Differentiation & 1.11 & 3.16 & -2.69 & 0.517 & 1.09 & 2.48 & -1.04 & 0.282 & 1.11 & 3.00 & -2.00 & 0.383 \\
\hline Perceptual processes & 2.24 & 2.64 & -0.27 & 0.820 & 1.96 & 2.79 & -0.64 & 0.309 & 2.17 & 2.67 & -0.35 & 0.714 \\
\hline See & 1.03 & 1.18 & -0.15 & 0.847 & 0.61 & 0.75 & -0.23 & 0.278 & 0.93 & 1.08 & -0.16 & 0.792 \\
\hline Hear & 0.67 & 0.80 & -0.14 & 0.831 & 0.87 & 1.35 & -0.54 & 0.260 & 0.72 & 0.93 & -0.23 & 0.697 \\
\hline Feel & 0.35 & 0.45 & -0.23 & 0.721 & 0.42 & 0.54 & -0.24 & 0.164 & 0.37 & 0.47 & -0.23 & 0.577 \\
\hline Biological processes & 1.82 & 2.14 & -0.17 & 0.927 & 1.47 & 2.11 & -0.53 & 0.275 & 1.74 & 2.13 & -0.22 & 0.856 \\
\hline Body & 0.73 & 0.75 & -0.02 & 0.886 & 0.90 & 1.14 & -0.28 & 0.267 & 0.77 & 0.84 & -0.07 & 0.774 \\
\hline Health & 0.78 & 0.87 & -0.07 & 0.910 & 0.22 & 0.38 & -0.40 & 0.132 & 0.65 & 0.75 & -0.09 & 0.889 \\
\hline Sexual & 0.06 & 0.10 & -0.14 & 0.761 & 0.02 & 0.06 & -0.28 & 0.059 & 0.05 & 0.09 & -0.15 & 0.725 \\
\hline Ingestion & 0.29 & 0.45 & -0.21 & 0.935 & 0.36 & 0.48 & -0.22 & 0.205 & 0.31 & 0.45 & -0.21 & 0.823 \\
\hline Drives & 5.72 & 7.89 & -1.05 & 0.711 & 5.77 & 7.57 & -0.73 & 0.310 & 5.73 & 7.82 & -0.96 & 0.590 \\
\hline Affiliation & 1.07 & 2.89 & -1.50 & 0.478 & 1.23 & 1.43 & -0.15 & 0.228 & 1.11 & 2.55 & -1.10 & 0.344 \\
\hline
\end{tabular}




\begin{tabular}{|c|c|c|c|c|c|c|c|c|c|c|c|c|}
\hline Achievement & 1.93 & 1.54 & 0.48 & 0.703 & 0.92 & 0.76 & 0.19 & 0.217 & 1.69 & 1.36 & 0.37 & 0.653 \\
\hline Power & 2.16 & 2.50 & -0.29 & 0.794 & 3.30 & 4.73 & -0.81 & 0.238 & 2.43 & 3.02 & -0.39 & 0.642 \\
\hline Reward & 0.95 & 1.13 & -0.32 & 0.468 & 0.71 & 0.73 & -0.03 & 0.195 & 0.90 & 1.04 & -0.25 & 0.435 \\
\hline Risk & 0.71 & 0.52 & 0.41 & 0.730 & 0.52 & 0.35 & 0.27 & 0.135 & 0.67 & 0.48 & 0.36 & 0.518 \\
\hline Relativity & 10.68 & 13.86 & -1.24 & 0.724 & 9.61 & 11.50 & -0.67 & 0.316 & 10.43 & 13.31 & -1.05 & 0.629 \\
\hline Motion & 1.95 & 2.07 & -0.13 & 0.632 & 2.00 & 2.22 & -0.23 & 0.164 & 1.97 & 2.10 & -0.15 & 0.502 \\
\hline Space & 3.32 & 7.43 & -2.45 & 0.767 & 2.88 & 6.25 & -1.89 & 0.301 & 3.22 & 7.16 & -2.26 & 0.654 \\
\hline Time & 5.86 & 4.54 & 0.80 & 0.663 & 5.34 & 3.15 & 1.22 & 0.254 & 5.74 & 4.21 & 0.88 & 0.554 \\
\hline \multicolumn{13}{|l|}{ Personal concerns } \\
\hline Work & 2.55 & 2.48 & 0.05 & 0.894 & 0.66 & 0.69 & -0.04 & 0.336 & 2.11 & 2.06 & 0.03 & 0.897 \\
\hline Leisure & 0.71 & 0.88 & -0.20 & 0.855 & 0.35 & 0.39 & -0.08 & 0.155 & 0.62 & 0.77 & -0.17 & 0.803 \\
\hline Home & 0.23 & 0.29 & -0.16 & 0.806 & 0.37 & 0.47 & -0.17 & 0.254 & 0.27 & 0.33 & -0.16 & 0.589 \\
\hline Money & 0.49 & 0.61 & -0.14 & 0.939 & 0.21 & 0.31 & -0.23 & 0.115 & 0.43 & 0.54 & -0.14 & 0.885 \\
\hline Religion & 0.13 & 0.20 & -0.16 & 0.924 & 1.45 & 3.34 & -1.09 & 0.332 & 0.44 & 0.93 & -0.36 & 0.713 \\
\hline Death & 0.14 & 0.20 & -0.19 & 0.879 & 0.26 & 0.40 & -0.33 & 0.206 & 0.17 & 0.25 & -0.22 & 0.668 \\
\hline Informal language & 0.85 & 0.41 & 0.77 & 0.473 & 0.80 & 0.48 & 0.50 & 0.002 & 0.84 & 0.43 & 0.70 & 0.341 \\
\hline Swear words & 0.01 & 0.03 & -0.27 & 0.268 & 0.00 & 0.02 & -0.37 & -0.027 & 0.01 & 0.03 & -0.29 & 0.227 \\
\hline Netspeak & 0.13 & 0.08 & 0.21 & 0.067 & 0.01 & 0.26 & -0.70 & -0.032 & 0.11 & 0.12 & -0.04 & -0.004 \\
\hline Assent & 0.12 & 0.13 & -0.05 & 0.408 & 0.06 & 0.16 & -0.28 & -0.046 & 0.11 & 0.14 & -0.13 & 0.211 \\
\hline Nonfluencies & 0.16 & 0.17 & -0.03 & 0.318 & 0.42 & 0.18 & 0.52 & 0.060 & 0.22 & 0.17 & 0.18 & 0.150 \\
\hline Filler words & 0.11 & 0.01 & 1.00 & 0.064 & 0.11 & - & - & - & - & - & - & - \\
\hline
\end{tabular}

Note. Relative word count is the proportion of dictionary word use to the total number of words in each text. J-LIWC2015 and LIWC2105 were used to analyze Japanese and English texts, respectively. Grand mean is the unweighted mean value across the TED Talks and the Bible texts. No filler words were counted in the Bible texts in English thus no equivalence check and grand mean calculation was made in the category. $g=$ Hedges' $g$ (unbiased Cohen's $d$ for two-sample $t$-test). $r=$ Pearson's correlation coefficient. 
Table S4. Mean values of manipulation check and personality variables in each condition.

\begin{tabular}{|c|c|c|c|c|c|c|c|c|c|}
\hline & $\begin{array}{c}\text { Episode } \\
\text { pleasantness } \\
-\end{array}$ & $\begin{array}{l}\text { Episode } \\
\text { Impact } \\
(\alpha=.69)\end{array}$ & $\begin{array}{l}\text { Positive affect } \\
\qquad(\alpha=.88)\end{array}$ & $\begin{array}{c}\text { Negative } \\
\text { affect } \\
(\alpha=.91)\end{array}$ & $\begin{array}{l}\text { Extraversion } \\
\qquad(\alpha=.87)\end{array}$ & $\begin{array}{l}\text { Conscientiousnes } \\
\text { s } \\
\qquad(\alpha=.93)\end{array}$ & $\begin{array}{l}\text { Neuroticism } \\
\qquad(\alpha=.88)\end{array}$ & $\begin{array}{l}\text { Openness } \\
\qquad(\alpha=.83)\end{array}$ & $\begin{array}{l}\text { Agreeablenes } \\
\text { s } \\
\quad(\alpha=.76)\end{array}$ \\
\hline Control (C) & 3.83 & 7.03 & 20.20 & 19.90 & 19.50 & 27.90 & 25.60 & 25.50 & 23.20 \\
\hline$(N=157)$ & $(1.24)$ & $(2.47)$ & $(7.30)$ & (8.92) & $(6.42)$ & (7.79) & $(5.73)$ & $(6.43)$ & $(5.83)$ \\
\hline Positive (P) & 5.38 & 10.30 & 26.80 & 20.10 & 19.50 & 28.40 & 24.00 & 25.20 & 22.10 \\
\hline$(N=164)$ & $(1.14)$ & (1.58) & $(7.63)$ & (8.34) & $(5.90)$ & $(6.68)$ & $(6.36)$ & (5.99) & $(5.05)$ \\
\hline Negative $(\mathrm{N})$ & 1.61 & 9.20 & 17.80 & 28.30 & 18.80 & 27.10 & 25.30 & 24.40 & 22.90 \\
\hline$(N=179)$ & $(0.94)$ & $(2.10)$ & (7.11) & $(9.37)$ & (6.35) & $(7.21)$ & $(5.54)$ & $(6.16)$ & $(5.69)$ \\
\hline$F(2,497)$ & 503.2 & 104.9 & 68.0 & 49.5 & 0.70 & 1.62 & 3.40 & 1.54 & 1.87 \\
\hline$p$ & $<.001$ & $<.001$ & $<.001$ & $<.001$ & .495 & .200 & .034 & .215 & .155 \\
\hline $99.5 \% \mathrm{Cl}(\mathrm{N}-\mathrm{C})$ & {$[-2.55,-1.87]$} & {$[1.53,2.81]$} & {$[-4.67,-0.14]$} & {$[5.63,11.12]$} & {$[-2.63,1.21]$} & {$[-3.05,1.41]$} & {$[-2.15,1.47]$} & {$[-3.04,0.78]$} & {$[-2.02,1.40]$} \\
\hline $99.5 \% \mathrm{Cl}(\mathrm{P}-\mathrm{C})$ & {$[1.21,1.90]$} & {$[2.66,3.96]$} & {$[4.29,8.91]$} & {$[-2.57,3.03]$} & {$[-1.99,1.93]$} & {$[-1.70,2.86]$} & {$[-3.46,0.24]$} & {$[-2.24,1.66]$} & {$[-2.89,0.59]$} \\
\hline $\begin{array}{c}\text { Multiple } \\
\text { comparison } \\
(\text { Holm; } p<.005)\end{array}$ & $\mathrm{P}>\mathrm{C}>\mathrm{N}$ & $\mathrm{P}>\mathrm{N}>\mathrm{C}$ & $\mathrm{P}>\mathrm{C}>\mathrm{N}$ & $\mathrm{N}>\mathrm{C}, \mathrm{N}>\mathrm{P}$ & & & & & \\
\hline
\end{tabular}

Note. Multiple comparison results were adjusted by Holm's method (adjusted $p<.005$ ). 
Table S5. Relative word counts (\% of total words) and correlations for linguistic categories in J-LIWC2015 and MeCab.

\begin{tabular}{lrrc}
\hline \multicolumn{1}{c}{ Category } & J-LIWC2015 & MeCab & \multicolumn{1}{c}{$r$} \\
\hline Verbs & 6.35 & 14.93 & 0.485 \\
Adverbs & 3.00 & 1.62 & 0.715 \\
Prenoun adjectival & 0.25 & 1.45 & 0.354 \\
Auxiliary verbs & 6.05 & 11.31 & 0.382 \\
Case particles & 30.01 & 30.80 & 0.683 \\
Filler words & 0.11 & 0.02 & 0.435 \\
\hline
\end{tabular}

Note. TED + Bible $(N=5887)$ Japanese corpus in Table S3 was analyzed. $r=$ Pearson's correlation coefficient. 